\title{
LOS ADVERBIOS EN -MENTE EN LOS REGISTROS FORMAL E INFORMAL DEL ESPAÑOL HABLADO PENINSULAR Y MEXICANO
}

\section{ADVERBS IN -MENTE IN FORMAL AND INFORMAL REGISTERS OF SPOKEN PENINSULAR AND MEXICAN SPANISH}

\author{
Carmen KortschaK \\ Universität Graz \\ carmen.kortschak@a1.net \\ Martin Hummel \\ Universität Graz \\ martin.hummel@uni-graz.at
}

Resumen: Se analizan los adverbios en -mente en el español peninsular hablado según criterios como la (in)formalidad y la educación. Los datos muestran que su frecuencia es tres veces mayor en el registro formal y en el nivel educativo superior. Estos resultados se comparan con datos del habla culta y popular en México. Llama la atención que la frecuencia de los adverbios es también tres veces más alta en el habla culta que en la popular. En el trabajo se explica el paralelismo de los hechos con la tradición escrita, que tiene mayor influencia tanto en el registro formal como en el habla culta.

Palabras clave: adverbios en -mente; registros formal e informal; tradi-

ción escrita; español hablado peninsular; español hablado mexicano.

Aвstract: The paper analyzes adverbs in -mente used in spoken Peninsular Spanish, according to criteria such as formality and educational level of respondents. The data shows that their frequency is three times higher in formal registers and three times higher at high educational levels. The results are compared to Mexican Spanish data (habla culta and popular), where the frequency is again three times higher at high educational levels. The paper suggests that the parallelism between these results is due to the impact of the written tradition on formal register and on educated speech.

Keywords: adverbs in -mente; formal and informal registers; written

tradition; Peninsular spoken Spanish; Mexican spoken Spanish.

Recepción: 21 de junio de 2016; aceptación: 14 de febrero de 2017.

D.R. () 2018. Nueva Revista de Filología Hispánica

Licencia Creative Commons Attribution-NonCommercial (CC BY-NC) 4.0 International 


\section{INTRODUCCIÓN}

Según ha demostrado Company Company (2012, 2014), con amplia documentación empírica, la enorme expansión de los adverbios en -mente está estrechamente vinculada con el desarrollo de una tradición escrita, y especialmente con el proceso de estandarización de la escritura (Hummel en prensa a). La lematización de 2821 adverbios con -mente en el diccionario de Seco et al. (1999), realizado a partir de un corpus de textos escritos del siglo $\mathrm{xx}^{1}$, pone de manifiesto el éxito diacrónico del proceso de expansión. Es llamativo al respecto que los adverbios en -ment(e) sólo se implementaron de forma sistemática y regular en las lenguas romances que primero establecieron una escritura neolatina: español, francés, italiano, portugués -lenguas acompañadas en esta fase por el catalán y el provenzal. Y tanto es así, que Company (en prensa; cf. Garcés Gómez 1998) constata que la desambiguación funcional y semántica de los adverbios en -mente implica de forma sistemática un contexto mucho más amplio que los adjetivos adverbiales. Ello quiere decir que los adverbios en -mente se usan en tejidos sintáctico-semánticos complejos. Tales estructuras se encuentran con mayor frecuencia en los textos escritos.

En cambio, las lenguas y variedades con fuerte o exclusiva tradición oral recurren a los llamados adjetivos adverbiales (también llamados adjetivos adverbializados o adverbios cortos), es decir, el uso del adjetivo con funciones adverbiales, como, por ejemplo, hablar claro y correr rápido, con modificación del verbo, o "típico" alemán, con modificación de un adjetivo, etc. Además, es éste el único proceso de formación de adverbios auténticamente panrománico. Por limitado que sea su uso en la lengua escrita estándar, este tipo de adverbio existe en todas las lenguas y variedades romances (Hummel 2013), y es exclusivo en sardo, rumano, los dialectos del sur de Italia y el francés de Luisiana, si excluimos algunos préstamos no productivos a las variedades estándares. Desde el punto de vista histórico-comparativo de reconstrucción de la diacronía, la omnipresencia de los adjetivos adverbiales es un indicador fuerte de su origen en

1 SAntos Río (2003) incluye 3161 adverbios en -mente diferentes, según nuestros cálculos. En el Diccionario del español de México (LARA 2010), hecho con un corpus escrito y oral del siglo xx, se enlistan 1008 adverbios en -mente, según la comunicación amable de Luis Fernando Lara. 
el latín hablado. Como consecuencia de la mayor continuidad de esta tradición oral, o sea, del menor impacto de los esfuerzos de estandarización, los adjetivos adverbiales predominan en la oralidad informal de los países hispanófonos y lusófonos del Nuevo Mundo, donde conforman el estándar oral informal (Hummel 2013). Así las cosas, -mente no es, como nos lo hacen creer los manuales, el sufijo adverbializador par excellence de las lenguas románicas, sino un elemento que sólo se desarrolló sistemáticamente en su tradición escrita.

Sin entrar en el análisis de la bibliografía general sobre el adverbio en -mente, que en realidad nada o poco toca a los aspectos variacionales (Egea 1979; Rainer 1993; Kovacci 1999; Rodríguez Ramalle 2003; Torner Castells 2007, entre otros), el presente trabajo se propone documentar y analizar el uso de los adverbios en -mente en el español hablado en la Península ibérica (inicios del s. Xxi) y en México (segunda mitad del s. Xx) en los registros formal e informal. Se supone que las realizaciones de la lengua en el registro formal se acercan más a la tradición escrita, con su preferencia por los adverbios en -mente, mientras que el mismo influjo se haría sentir menos en el registro informal (o los registros informales). Dicho de otro modo, partimos de la idea de que la historia de la lengua ha dejado sus huellas en la variación sincrónica actual.

Antes de entrar in medias res, conviene definir los conceptos principales. Según Briz Gómez (1998), los registros son variantes situacionales que conforman un continuum entre dos polos ideales, la formalidad y la informalidad:

Convencionalmente y en abstracto se pueden distinguir dos tipos de registros, el formal y el informal-coloquial, los cuales podrían ser entendidos como dos extremos imaginarios, dentro del continuum de manifestaciones de habla según la situación de comunicación, extremos, aunque no límites, a uno y otro lado del continuum (p. 26).

En este sentido, el autor distingue el español hablado informal-coloquial del formal. La informalidad se define según los siguientes parámetros situacionales: +proximidad, +cotidianidad, +espontaneidad (= bajo grado de planificación), +saber compartido, +finalidad interpersonal. La formalidad se corresponde con los criterios -proximidad, +planificación, -cotidiani- 
dad, +finalidad transaccional (Briz Gómez 1998, pp. 26 ss.). El autor especifica, además:

En ocasiones coloquial se ha utilizado erróneamente como sinónimo de vulgary popular... llamamos coloquial, entendido como nivel de habla, a un uso socialmente aceptado en situaciones cotidianas de comunicación, no vinculado en exclusiva a un nivel de lengua determinado y en el que vulgarismos y dialectalismos aparecen en función de las características de los usuarios (pp. 36 ss.).

La distancia, el control y la finalidad comunicativa son vectores que en las situaciones formales favorecen un comportamiento lingüístico que prefiere las variantes consideradas más correctas o más prestigiosas. Por este motivo, suponemos que se usen más los adverbios en -mente en este registro. Además, el dominio de las normas lingüísticas presupone no solamente la alfabetización en sentido estricto, sino una educación lingüística ya elaborada. Por eso, suponemos además que la preferencia por los adverbios en -mente dependerá del nivel educativo.

Para comprobar las hipótesis, exploramos el subcorpus español de C-Oral-Rom (Cresti \& Moneglia 2005). Los resultados generales, que se presentan después de esta exploración, vienen luego a ser diferenciados según las variables "formalidad/ informalidad" y "nivel educativo". Estos datos se cruzan a continuación con los criterios "posición/ función sintáctica" y "función semántico-pragmática" de los adverbios. Después, los datos peninsulares se comparan, en lo posible, con datos americanos ya disponibles provenientes de México. Finalmente, se relaciona el empleo de los adverbios en -mente peninsulares con la estructura interna de los subcorpus formal e informal, que reúnen diferentes tipos de texto, para abrir asimismo nuevas perspectivas que contribuyan a la investigación futura.

El trabajo pertenece a una serie de estudios sobre la interficie de adjetivo y adverbio en las lenguas románicas². Se utilizan los datos de Kraschl (2008), la coautora del presente estudio, ahora llamada Kortschak.

${ }^{2}$ Véase https://adjective-adverb.uni-graz.at. Este trabajo se enmarca en el proyecto "Oralia Diacrónica del Español (ODE)" de la Universidad de Granada (FFI2013-46207P), concedido por el Ministerio de Economía y Competitividad y los Fondos Feder. 


\section{Corpus}

\section{Datos europeos}

El corpus contrastivo Integrated Reference Corpora for Spoken Romance Languages, o C-Oral-Rom (Cresti \& Moneglia 2005), permite un análisis del uso oral de los adverbios en -mente en el español actual, tal y como se observa a principios del siglo xxi en España. La repartición de los datos en textos formales e informales y en niveles educativos de los hablantes, definidos por los años de escolaridad, presenta las condiciones necesarias para verificar o deponer nuestras hipótesis. La parte aquí analizada, que suma 270854 palabras, corresponde al subcorpus español. Con cerca de 150000 palabras, el corpus informal es algo más grande que el formal, con 120000.

C-Oral-Rom distingue los textos según la situación (media, natural context, telephone, family private, public) ${ }^{3}$, el tipo de comunicación (dialogue, monologue, conversation), el medio (telephone, face to face), la edad y el sexo de los hablantes, la actividad profesional, la escolarización y el origen geográfico. La edad de los hablantes viene indicada según cuatro grupos: A (18-25), B (25-40), C (40-50) y D (60 y más). El grado de escolarización es señalado con 1 (primary school o illiteracy), 2 (high school) y 3 (graduates o university students) ${ }^{4}$. Casi la mitad de los hablantes proviene de Madrid y región (188), otros 161 no son especificados; 61 hablantes son oriundos de otras regiones de España o Hispanoamérica -la mayoría de los hispanoamericanos son inmigrantes que residen en España desde hace varias décadas.

Como es de esperar, la clasificación de los textos según los criterios de formalidad/ informalidad no es tarea fácil. En efecto, la definición teórica de Briz Gómez citada supra sitúa los datos en un continuum en el que estos criterios conforman los dos polos. Ello quiere decir que la clasificación de los textos, a partir de los criterios de formalidad e informalidad, implica cierta arbitrariedad, sin hablar del hecho de que la clasificación de textos completos no tiene en cuenta el grado de (in)formalidad de los actos de habla que los conforman. Sin embargo, un

${ }^{3}$ Hemos decidido usar los términos provenientes del inglés por su correspondencia inequívoca con el banco de datos.

4 1, educación primaria (6-12 años de edad) y analfabetismo; 2 , educación secundaria (12-16/18 años de edad); 3, educación superior (18+ años de edad). 
corpus con tamaño suficiente debería poner en claro las tendencias generales, si éstas son bien marcadas y manifiestas en la lengua. Respetamos, pues, las clasificaciones del corpus (Cresti \& Moneglia 2005, pp. 10-11), con una excepción. Hemos clasificado las llamadas telefónicas bajo los textos informales, ya que el lenguaje empleado no tiene nada de formal ${ }^{5}$. Con esta modificación, el corpus del habla informal tiene dos veces el tamaño del corpus formal (180 010 frente a 90844 palabras). Por eso, nos referiremos a la frecuencia relativa de las formas en cada corpus.

Según Cresti y Moneglia (2005), la subcategorización de los textos formales en tipos de texto no puede ser la misma que la de los textos informales:

While it is natural to assume the existence of a series of closed situations in which, in a certain social-historical context, the formal use of language is preferred, the same does not hold for the universe of informal speech. To feature typical contexts of use is a specific, marked trait of formal speech. For this reason, formal speech can be effectively identified by listing its most typical contexts of use. Conversely, the set of situations where informal language is used is open, and its domain cannot be represented by a list of typical contexts of use (p. 13).

Así, por ejemplo, los textos de la subcategoría "natural context" provienen exclusivamente de hablantes del grupo 3 (nivel universitario). Ante la imposibilidad de discriminar los textos informales según los tipos de contexto, los autores los clasifican según su carácter monologal, dialogal o conversacional. Volveremos a las características internas de los subcorpus en un apartado posterior, dedicado a la frecuencia de los adverbios en -mente según el tipo de comunicación/ texto en el habla formal e informal.

5 Creemos que Cresti y Moneglia tomaron el término lengua de distancia de Koch y Oesterreicher (2007), claramente metafórico, al pie de la letra en el caso de la comunicación por teléfono, es decir, un medio que presupone una distancia local, aunque no necesariamente afectiva. Seguimos la clasificación propuesta por BRIz GómEz (1998) de las conversaciones telefónicas como registro básicamente informal, teniendo en cuenta, además, el lenguaje efectivamente empleado en las conversaciones del corpus, que es informal-coloquial. 


\section{Datos americanos}

El análisis de los adverbios en -mente en el habla mexicana efectuado por Vigueras Ávila (1983) y Arjona Iglesias (1991) nos sirve de punto de referencia para contrastar nuestros resultados con esta variedad hispanoamericana. Arjona Iglesias utiliza el corpus del "habla popular" de México (ciudad), con cerca de 17 horas de grabación de entrevistas, y compara estos datos con el corpus del habla culta de la Ciudad de México del mismo tamaño (proveniente del Proyecto PILEI, coordinado por Juan M. Lope Blanch; véase Samper Padilla 2014), analizado previamente por Vigueras Ávila. Debido a la situación de entrevista del Proyecto PILEI, que favorece ampliamente el uso de un lenguaje culto, cuidado, el corpus del habla culta corresponde al registro oral formal, pese a que los hablantes cultos dispongan también del registro informal, prácticamente sin usarlo en las entrevistas.

\section{La comparación de los datos}

La comparación de los datos europeos con los americanos tendría que referirse a una base común. Ahora bien, C-Oral-Rom indica el número de palabras al paso que los corpus americanos toman como referencia las horas de grabación. Cresti y Moneglia $(2005$, p. 1) se refieren a un total de 122 horas de grabación para las cuatro lenguas. Tendríamos, pues, y muy aproximadamente, cerca de 30 horas de grabación para el español peninsular, o sea, un tamaño que se acerca al de los dos subcorpus mexicanos juntos (34 horas). Puesto que el corpus francés de C-Oral-Rom es algo más reducido, podemos arriesgarnos a decir que los corpus son más o menos de la misma extensión. Sin embargo, el número de palabras sería la única referencia operacional en términos contrastivos, ya que trabajaremos con frecuencias de palabras.

El hecho de diferenciar los registros formal e informal, en el primer caso, y el habla culta de la popular, en el segundo, impide la comparación desde el punto de vista de las bases cualitativas de la cuantificación. Además, los hablantes del corpus popular intentan también 'hablar bien', es decir, la formalidad no es un aspecto ausente en este corpus. Lo que acerca los datos "populares" mexicanos a los "informales" peninsulares 
es, inicialmente, la dificultad de los informantes para elaborar discursos formales como los que se observan con los hablantes cultos. Por añadidura, C-Oral-Rom es un corpus compuesto por diferentes tipos de texto, mientras que los corpus americanos sólo contienen entrevistas.

Hemos optado por tener en cuenta los datos mexicanos pese a la asimetría metodológica que se encuentra en la base de los corpus europeo y mexicano. Nuestro estudio no está concebido para comparar directamente los datos europeos con los americanos. Lo que nos interesa, fundamentalmente, es comparar la estructura interna de los corpus peninsular y mexicano en términos de repartición de criterios. Luego se puede argumentar que la tradición oral descrita en la introducción tiene mayor impacto tanto en la lengua oral informal en general como en el habla popular. Veamos lo que nos permiten decir los datos.

LA FRECUENCIA GENERAL DE LOS ADVERBIOS

EN -MENTE EN EL HABLA PENINSULAR

En el habla de C-Oral-Rom, unidos todos los registros, hemos encontrado 1461 adverbios en -mente, que corresponden al $0.47 \%$ de las 313330 palabras del corpus. Dicho de otra manera, este tipo de adverbios aparece una vez cada 214 palabras. Los 1461 ejemplares (tokens) se realizan con solamente 233 lexemas distintos (frecuencia del type), cuya relación type/ token es de 0.16. Esta cifra indica un alto grado de uso. En efecto, cada lexema tiene una media de 6.3 ocurrencias en el corpus, número que corresponde a la relación token/ type.

Ahora bien, el promedio matemático oculta la repartición muy desigual de las ocurrencias. En un extremo, el 60\% de los types, que corresponden a 140 adverbios diferentes, ocurren dos veces o menos. En el otro extremo, los diez adverbios más frecuentes reúnen el $36.6 \%$ de los tokens, según se desprende del Gráfico 1: 


\section{GRÁFICO 1}

Frecuencia relativa en porcentaje de los diez adverbios más frecuentes en C-Oral-Rom $(N=1461)$

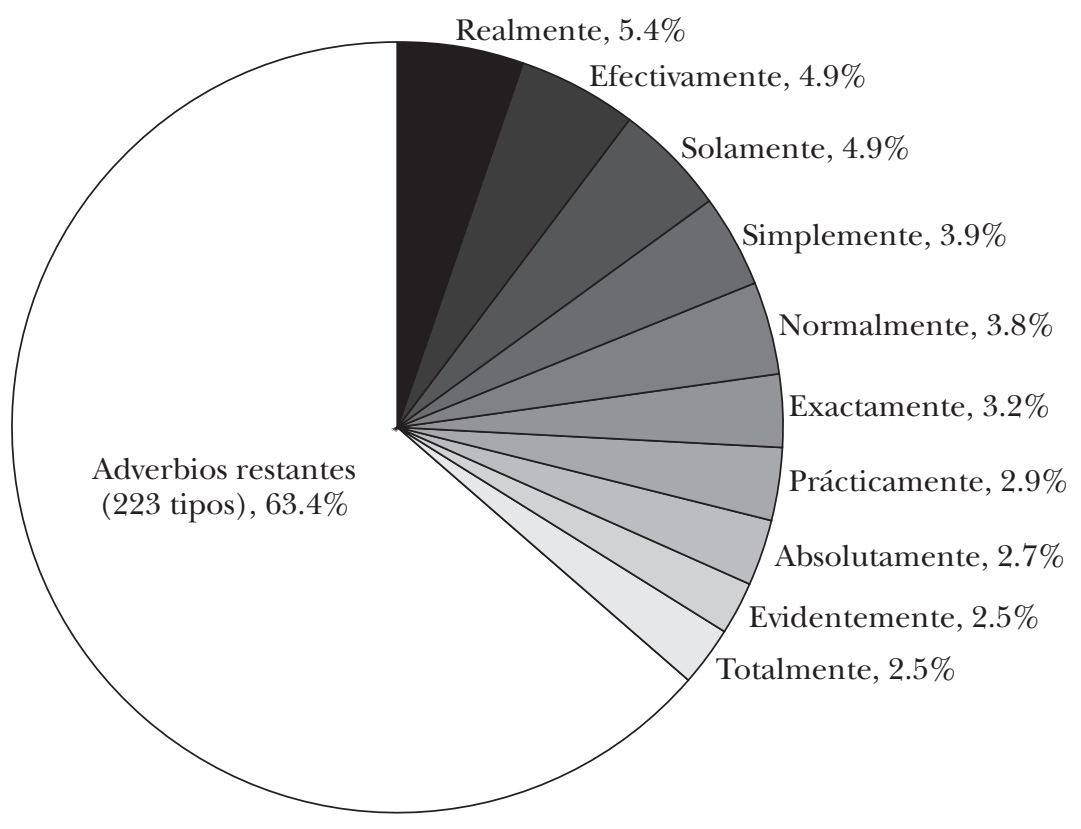

La relación type/ token de las diez unidades más frecuentes es $10 / 535=0.019$, cifra que indica un uso muy elevado. Es decir, la ocurrencia media de cada una de estas unidades es de 53.5 ejemplares en el corpus. Se trata de unidades altamente polifuncionales y polisémicas que realzan funciones discursivas de organización del texto, de enfoque y de énfasis ${ }^{6}$. La polifuncionalidad y polisemia de estas unidades son tanto la consecuencia de su frecuencia de uso como el motor de su uso frecuente, en la medida en que los lexemas en boga suelen expandirse hacia nuevas funciones ${ }^{7}$.

6 Véase Kraschl 2008, pp. 85-99.

7 Véase, por ejemplo, el desarrollo del marcador discursivo fijo, HuMMEL 2012, pp. 164-167; cf. Thompson y Mulac 1991. 
LA FRECUENCIA DE LOS ADVERBIOS EN -MENTE EN EL HABLA FORMAL E INFORMAL

Si distinguimos los datos según los criterios de (in)formalidad, descubrimos otra repartición desigual. Según lo que deja interpretar el Gráfico 2, la frecuencia relativa de estos adverbios corresponde al $0.75 \%$ de las palabras en los textos formales, y al $0.27 \%$ en los textos informales. En otras palabras, los adverbios en -mente se dan tres veces más en los textos formales:

\section{GRÁfICo 2}

Frecuencia relativa en porcentaje de los adverbios en -mente en C-Oral-Rom según los registros formal (columnas a la izquierda) e informal (columnas a la derecha) $(N=1461)$

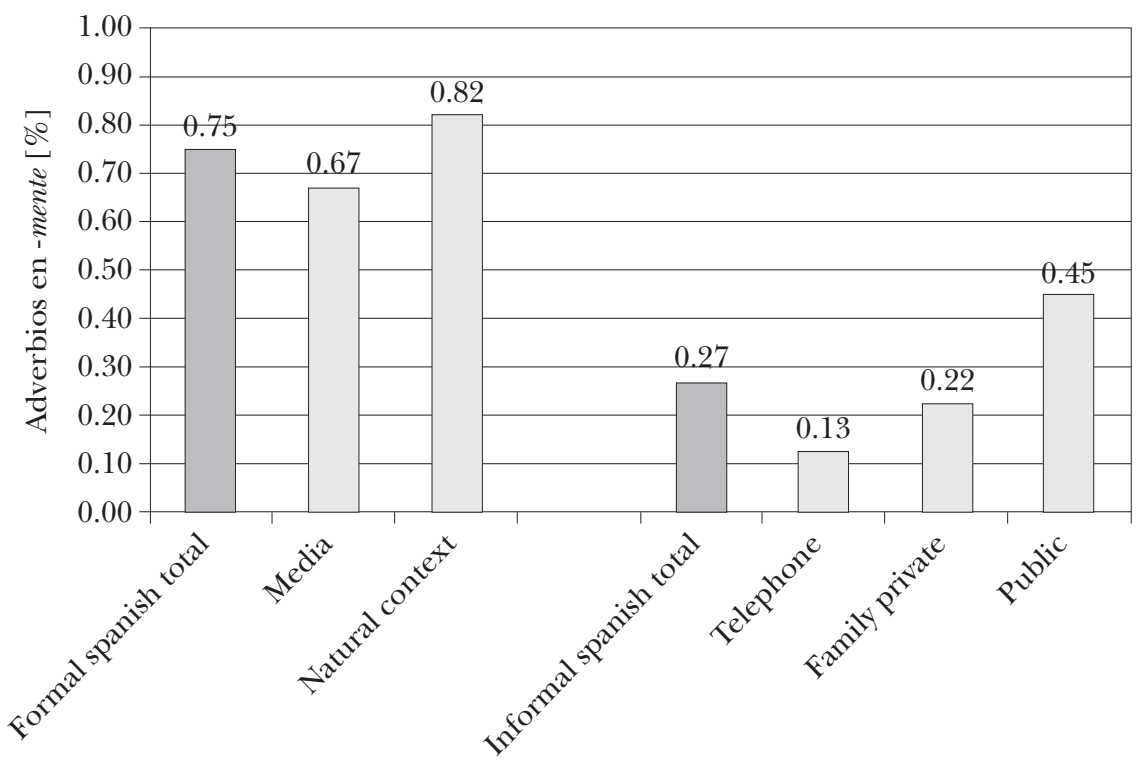

La mayor representación de los adverbios en -mente en el habla formal confirma nuestra hipótesis de su uso preferencial en los registros formales. Llama la atención que, dentro de los textos informales, los adverbios en -mente sean dos veces más frecuentes en los textos públicos que en la comunicación en familia. La exposición al control social parece provocar una mayor preferencia por los adverbios en -mente favorecidos por la norma. Mencionemos que la exploración variacional del Corpus de référence du français parlé da resultados muy parecidos en lo que ata- 
ñe a la repartición del uso de los adverbios en -ment según los criterios public-private (Bilger 2004).

En la Ciudad de México, la proporción de adverbios en -mente en el corpus del habla culta (950 tokens) frente al habla popular (299 tokens) es evidentemente análoga a la que se observa en Europa respecto de los registros formal e informal, esto es, tres veces más alta en el estrato culto. En la misma línea, el control social parece favorecer el uso de -mente. De hecho, 278 de los 299 adverbios en -mente, o sea, el 93\%, registrados en el habla popular mexicana (Arjona Iglesias 1991, p. 29), ocurren en situaciones comunicativas en las que los hablantes sabían que estaban siendo grabados. Es decir, son catorce veces más frecuentes en este tipo de situaciones. Según Arjona Iglesias, la presencia de un entrevistador y la inminencia de una grabación inducen a los hablantes a emplear un estilo más formal:

hay considerablemente más testimonios [de adverbios en -mente] por informante en encuestas no secretas que en grabaciones secretas, lo cual puede ser reflejo, aventuraría yo, de un afán de los informantes de habla popular por hacer su discurso más elegante o por lo menos más cercano al de la norma de prestigio, a la cual, además, pertenece la persona que les hace la encuesta (Arjona Iglesias 1991, pp. 29-30; cf. p. 40).

De hecho, los hablantes mexicanos dicen preferir los adverbios en -mente cuando sienten la necesidad de expresarse con mayor formalidad, pues los consideran como variante de "prestigio", como suele decirse. La noción de prestigio, que poco se usa en España, es pertinente para la conciencia lingüística de los mexicanos ${ }^{8}$. El mismo comportamiento nos fue reportado en Brasil (Hummel 2002).

La vinculación con la lengua de prestigio se confirma también en un corpus de llamadas telefónicas del ámbito uruguayo, donde los adverbios en -mente se usan de modo bastante sistemático para efectos de cortesía formal (Hummel 2012, pp. 308310). Este rasgo, característico del español y del portugués en América, sorprende al observador europeo que asocia el empleo de este tipo de adverbios a la lengua estándar sin connotaciones mayestáticas. No nos olvidemos, sin embargo, de que estos adverbios se usaban como formas de prestigio en Europa, poco más o menos, hasta la mitad del siglo XVII (Hummel 2012, pp. 310-315).

${ }^{8}$ Véase Lope Blanch 1986. 
Si bien los textos formales peninsulares se diferencian de los informales por una frecuencia tres veces más alta de los adverbios en -mente, los diez adverbios más comunes son exactamente los mismos en los dos subcorpus, según se desprende de los Gráficos 3 y 4:

\section{GrÁFICO 3}

Frecuencia token en porcentaje de los diez adverbios más frecuentes (registro formal) $(N=1032)$

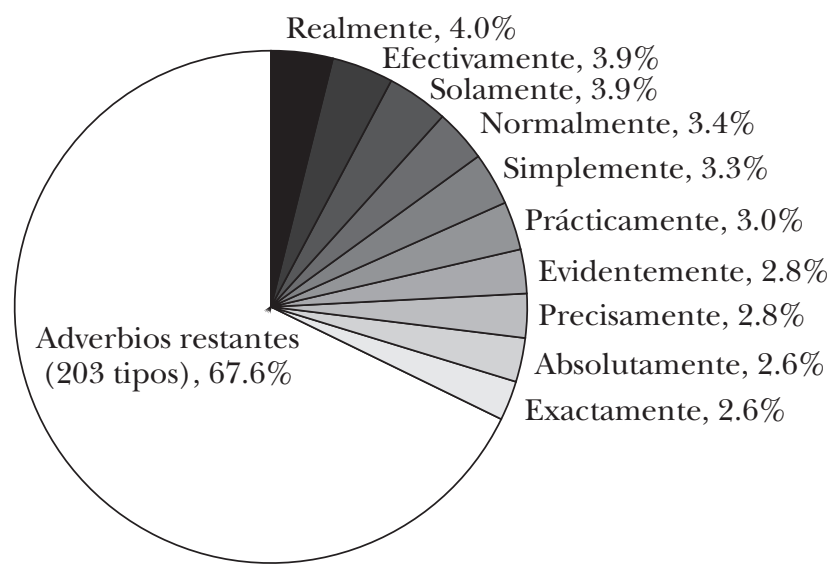

\section{GrÁFICO 4}

Frecuencia token en porcentaje de los diez adverbios más frecuentes (registro informal) $(N=429)$

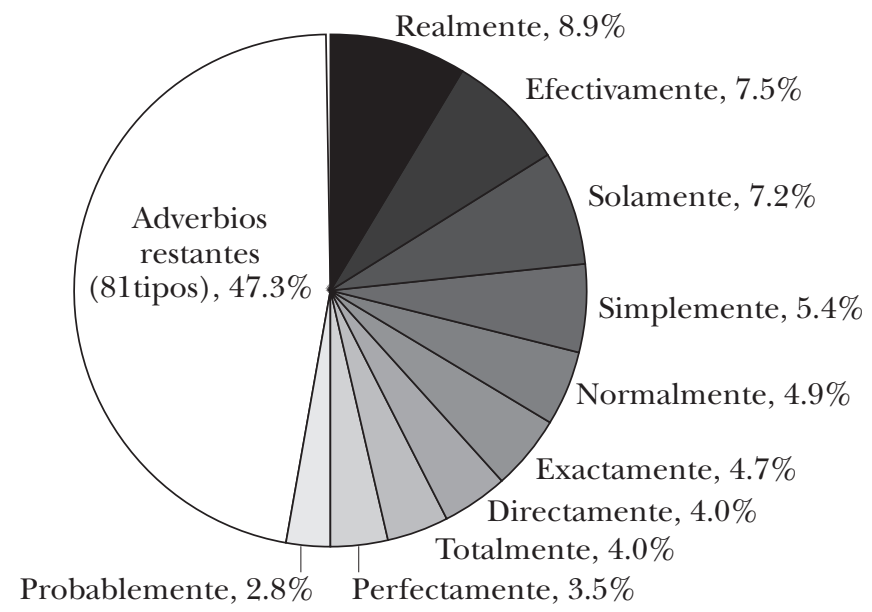

Nueva Revista de Filología Hispánica (NRFH), LXVI, 2018, núm. 1, 3-42

ISSN 0185-0121; e-ISSN 2448-6558; DOI: 10.24201/nrfh.v66i1.3391 
Según hemos visto, se trata de adverbios que se usan para situar lo dicho (epistémicos, actitudinales, organizadores de la argumentación, enfáticos, etc.). Podemos constatar, pues, que la organización del discurso y la estructuración de la información mediante este tipo de adverbios es fundamentalmente la misma tanto en los textos formales como en los informales. En consecuencia, se trata de una característica general de los textos orales. Son éstos los tipos de adverbio que con mayor profundidad penetraron la oralidad durante el proceso histórico de expansión de los adverbios en -mente, al margen del grado de formalidad. Si tenemos en cuenta, además, que la expansión diacrónica de los adverbios en -mente fue una tendencia culta relacionada con el desarrollo de la escritura y su estandarización, podemos suponer que la elevada frecuencia de los adverbios con funciones discursivas en la actualidad es el resultado de una difusión escritura-oralidad. Lógicamente, tal difusión se habrá dado primero en el habla culta. De hecho, todos los lexemas más frecuentes en los Gráficos 3 y 4 son préstamos del latín clásico y/o la continuación del latín tardío culto, con excepción de solamente, documentado desde el siglo viII en las Glosas de Reichenau (cf. Hummel 2013a y 2014b).

Ahora bien, si pasamos del análisis estrictamente cualitativo al cuantitativo, vemos que la proporción de uso de las diez unidades más frecuentes en los registros formal e informal discrepa notoriamente, con $32.4 \%$ para el primer caso y $52.7 \%$ para el segundo. Además, la frecuencia type es de 213 adverbios en -mente distintos en los textos formales, frente a tan solamente 91 en los informales. Ello quiere decir que los textos formales utilizan este tipo de adverbios de modo mucho más diferenciado.

Ante estos hechos, las diferencias en la jerarquía frecuencial interna de las diez unidades más frecuentes y la mayor concentración de las ocurrencias en las cinco unidades más frecuentes del subcorpus informal son fenómenos secundarios. El Gráfico 5 muestra que la principal diferencia es la frecuencia de uso, no la proporción de uso documentada en los Gráficos 3 y 4.

Por atractiva que parezca la extrapolación, la constatación de un uso más diferenciado de los adverbios en -mente en el corpus formal frente al informal no significa necesariamente que en términos generales la comunicación formal sea más diferenciada en la función adverbial. Para determinarlo con objetividad, habría que añadir un análisis onomasiológico de todas las unidades con función adverbial. Según la terminología usada 


\section{GRÁfICO 5}

Frecuencia token en porcentaje de los diez adverbios más frecuentes (registros formal e informal) $(N=1464)$

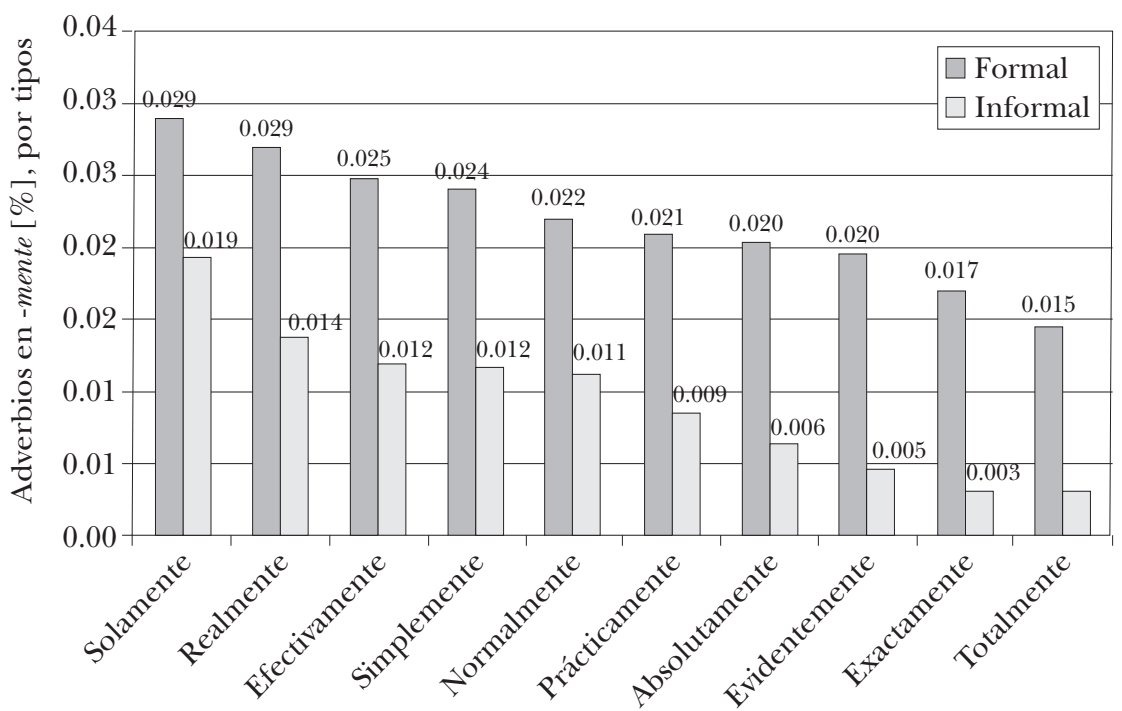

en las publicaciones de nuestro grupo de investigación, se pueden distinguir cuatro tipos morfosintácticos de adverbios: el Tipo A (hablar rápido), el Tipo B (hablar rápidamente), el perifrástico Tipo $\mathrm{C}$ (hablar con rapidez, de manera rápida, a la ligera) y los adverbios lexemáticos del Tipo D (hablar bien). La elevada frecuencia del Tipo A en el lenguaje informal nos obliga a ser prudentes a la hora de sacar conclusiones a partir del uso de los adverbios del Tipo B, especialmente porque las funciones discursivas más frecuentes que caracterizan a los adverbios en -mente se observan también en las unidades del Tipo A de mayor frecuencia, como son los marcadores discursivos orales claro, bueno, total, etc. Tampoco hay que ignorar la frecuencia del Tipo C en algunos casos (v.gr. por cierto, por lo pronto, etc.). De momento, sólo podemos limitarnos a la perspectiva semasiológica vinculada con el Tipo B y dejar para el futuro su ampliación onomasiológica. Nos parece importante prevenirnos de conclusiones precipitadas que juzguen la lengua oral coloquial como menos elaborada. El hecho de que las gramáticas y los trabajos que estudian los adverbios consideren en primer lugar los adverbios en -mente puede inducir el error. 
LA FRECUENCIA DE LOS ADVERBIOS EN -MENTE

SEGÚN EL NIVEL DE ESCOLARIDAD

\section{El uso peninsular}

Los datos metalingüísticos de este corpus distinguen tres niveles de escolaridad: 1 (escuela primaria/ analfabetismo), 2 (selectividad $^{9}$ ) y 3 (universidad, estudiantes incluidos), según hemos visto. No se dispone de datos para cada hablante, ya que no siempre fue posible conocer el nivel educativo de los participantes de un debate televisivo, pero los datos disponibles permiten sacar algunas conclusiones. En el subcorpus formal, el tipo de texto scientific press y la mayoría de los textos natural context presuponen un alto nivel educativo. En consecuencia, no podemos diferenciar el uso de los adverbios en -mente según criterios educativos en estos textos.

Los textos informales conversations y dialogues del grupo family private son más heterogéneos $\mathrm{y}$, por tanto, más adecuados para observar el posible impacto del grado de escolaridad. A diferencia de nuestra hipótesis, en los textos de este subcorpus no se observa ninguna tendencia general de los hablantes cultos al uso preferencial de adverbios en -mente. Sin embargo, todos los hablantes que muestran una predilección por este tipo de adverbios pertenecen al estrato más cultivado. Estos resultados, aparentemente contradictorios, se explican por las preferencias individuales en ese sector. En efecto, no todos los hablantes del grupo educativo 3 se distinguen al respecto del conjunto de los hablantes, pero algunos sí. En consecuencia, el hecho generalizable sería que la opción individual de usar con mayor frecuencia los adverbios en -mente es característica de los hablantes cultos. Asimismo, quienes dentro de esta categoría tienen una preferencia marcada por usar los adverbios en -mente se acercan al estándar de escritura. No obstante, también hay quienes, desentendiéndose de generalidades, no consideran la situación comunicativa motivo suficiente para pasar al registro formal.

La situación se reproduce de forma idéntica en la subcategoría informal de los monologues en el grupo family private: la preferencia por usar o no los adverbios en -mente es característica básicamente idiolectal o individual-situacional, pero todos los hablantes que efectivamente tienen una predilección por este

${ }^{9}$ En España, selectividad es el examen de ingreso a la universidad. 
tipo de adverbio corresponden al nivel 3. Es preferible hablar de opción individual-situacional, ya que un idiolecto se manifiesta por medio de una serie de discursos individuales, representativa de toda la variedad observable en la actividad lingüística de una persona. Por eso, la exploración de un solo texto individual en C-Oral-Rom refleja una opción individual-situacional, posiblemente única, que no permite ningún tipo de extrapolación idiolectal. En la categoría public (dialogues, conversations), los tres hablantes con mayor frecuencia de uso pertenecen también al estrato culto 3. El escaso número de textos en la categoría monologues (dos únicamente) no permite un análisis diferenciado.

Finalmente, se observa que el uso preferencial que hacen algunos hablantes cultos de los adverbios en -mente sólo se muestra en los tipos de discurso que lo permiten. Los news, weather forecasts y telephone conversations usan poco estos adverbios, independientemente del nivel educativo. Ante el imperativo de una comunicación económica, todos los hablantes siguen los mismos patrones. Ello viene a mostrar que el tipo de texto condiciona el uso de los adverbios en -mente por motivos ajenos al registro y al código empleados.

\section{El uso americano}

En el habla de la Ciudad de México, la frecuencia de los adverbios en -mente es también tres veces mayor en los hablantes cultos que en los de habla popular, tanto en la frecuencia token como en la frecuencia type (Arjona Iglesias 1991, p. 30). En su corpus del habla culta de la Ciudad de México, de dimensiones y características comunicativas idénticas al corpus popular, Vigueras Ávila (1983) detecta 950 adverbios en -mente. Las 950 ocurrencias (tokens) corresponden a 162 lexemas distintos (types), en tanto que los 299 tokens del corpus popular se realizan con 59 types. En otras palabras, el habla culta se presenta como tres veces más diferenciada que la popular. Además, el uso de adverbios en -mente como "muletillas" es más amplio en el habla popular que en la culta (16\% vs. $5.6 \%$; Arjona Iglesias 1991, p. 40). Teniendo en cuenta que el grupo de las llamadas muletillas se asemeja grosso modo al grupo de las unidades más frecuentes en el habla peninsular (véase supra), podemos afirmar que la situación en México es notoriamente análoga. 
No se observan diferencias significativas respecto a los criterios de sexo y edad en el corpus popular. En cambio, las diferencias individuales en sí aparecen con claridad:

El hecho más notable es... el que haya hablantes que utilizan con mucha frecuencia adverbios en -mente mientras que muchos otros $(19.5 \%)$ apenas producen un ejemplo y algunos más $(8.5 \%)$ ni uno solo (Arjona Iglesias 1991, p. 27).

La variación individual no es, como en el corpus peninsular, una característica de los hablantes cultos. Según la autora (véase supra), la variación individual popular refleja el esfuerzo de algunos hablantes por usar los adverbios en -mente como variantes prestigiosas en una situación de entrevista. En consonancia con esta interpretación, Arjona Iglesias (1991, p. 33) observa:

los informantes de habla popular emplean los adverbios en -mente de una manera un tanto asistemática, como si consideraran que dichos adverbios no pertenecen cabalmente a su sociolecto, al tiempo que los hablantes cultos los usan en abundancia y parecen sentirse muy cómodos con su empleo.

En Europa, donde los adverbios en -mente se consideran variante estándar, la frecuencia más elevada en algunos hablantes cultos se explica mejor como esfuerzo para evitar las variantes informales del tipo bueno, claro, etc. (marcadores discursivos) o ir directo (modificador de verbo), poco aceptadas en la escritura estándar. Según Medina Gómez y Alarcón Neve (2013, p. 69), en el español de México el adjetivo adverbial no se percibe con esta connotación negativa.

En México, la escritura estándar sigue las mismas pautas que en Europa, pero la expresión oral común prefiere los adjetivos adverbiales. En este sentido, Medina Gómez y Alarcón Neve (2013, p. 64) observan que el $90 \%$ de los adverbios modificadores de un verbo en el subcorpus escrito de CREA (México) termina en -mente, y el $10 \%$ son adjetivos adverbiales. La proporción se invierte en el Corpus sociolingüístico de la Ciudad de México (CSCM) con textos orales, donde los adjetivos adverbiales reúnen el $85 \%$ de las ocurrencias frente al $15 \%$ en el caso de los adverbios con sufijo. Estas tendencias generales no excluyen las excepciones, ya que estamos hablando de unidades generalmente lexicalizadas. Así, hablar alto/ bajo pertenecen 
tanto al estándar de escritura como al uso oral informal. Otro caso se da en el habla de la Ciudad de México (CSCM), donde directamente prevalece sobre directo (adv.), y fácilmente tiene casi la misma frecuencia que fácil (adv.) (pp. 65-66). Con todo, la tendencia general es muy clara: en los textos escritos se prefieren los adverbios en -mente a los adjetivos adverbiales en una proporción de 90 a 10, mientras que la relación se invierte en el habla, donde la misma relación es de 15 a 85 sobre 100 casos.

EL USO DE LOS ADVERBIOS EN -MENTE

SEGÚN SU FUNCIÓN SINTÁCTICA

\section{Clasificación y problemas metodológicos}

Según la terminología que se emplee, los adverbios en -mente se consideran modificadores o atributos de otras unidades. Además, en algunas de sus funciones discursivas se acercan a la de circunstantes. Así, por ejemplo, históricamente es un adverbio de perspectivación que define el marco en el que el hablante sitúa el contenido proposicional (Históricamente, la situación se presenta diferente), esto es, sirve para plantear una circunstancia discursiva. Con base en lo anterior, hemos clasificado los adverbios de C-Oral-Rom según las unidades modificadas:

$\begin{array}{ll}\text { (K1) } & \text { verbo } \\ \text { (K2) } & \text { enunciado } \\ \text { (K3) } & \text { adjetivo } \\ \text { (K4) } & \text { adverbio (adverbiales) } \\ \text { (K5) } & \text { sustantivo } \\ \text { (K6) } & \text { participio } \\ \text { (K7) } & \text { pronombre } \\ \text { (K8) } & \text { sintagma preposicional }\end{array}$

hablar solamente
solamente que
solamente azul
solamente deprisa
solamente hombres
solamente cansado
él solamente
solamente a las tres horas

Ilustramos las categorías con ejemplos construidos que no constan en el corpus, para poner en evidencia que la polifuncionalidad de un lexema como solamente tiene consecuencias para la frecuencia, en la medida en que la posibilidad de usarlo en muchas posiciones sintácticas aumenta la probabilidad de una frecuencia general más elevada de lo normal. Además, no hemos incluido ni la posibilidad de colocar solamente antes de los núcleos sintagmáticos (solamente hablar/ hablar solamente) ni 
la de usar pausas prosódicas o la entonación para modular el alcance y el tipo de atribución. Finalmente, resulta importante, desde el punto de vista metodológico, tener en cuenta la lexicalización, en el caso de solamente, tanto de un significado distinto ('exclusivamente') del original ('sin compañía'), como de funciones como la modificación determinativa (solamente tres), en este caso con posibles efectos de mitigación (atenuación) o intensificación (Solamente ellos saben hacerlo). Por eso, la clasificación según criterios exclusivamente sintácticos conduce a grupos heterogéneos desde el punto de vista semántico-pragmático y funcional. De este modo, resulta problemático clasificar hablar solamente como atributo de manera, en analogía con hablar tranquilamente. No obstante, el uso semánticamente específico de solamente dentro del sintagma verbal no es tan frecuente, ni lo es en otras unidades, como para invalidar las tendencias generales.

La frecuencia de los tipos sintácticos en los textos formales e informales

El Gráfico 6 representa las frecuencias de uso en la expresión formal:

\section{GrÁFICo 6}

\section{Los adverbios en -mente según las unidades modificadas} (registro formal)

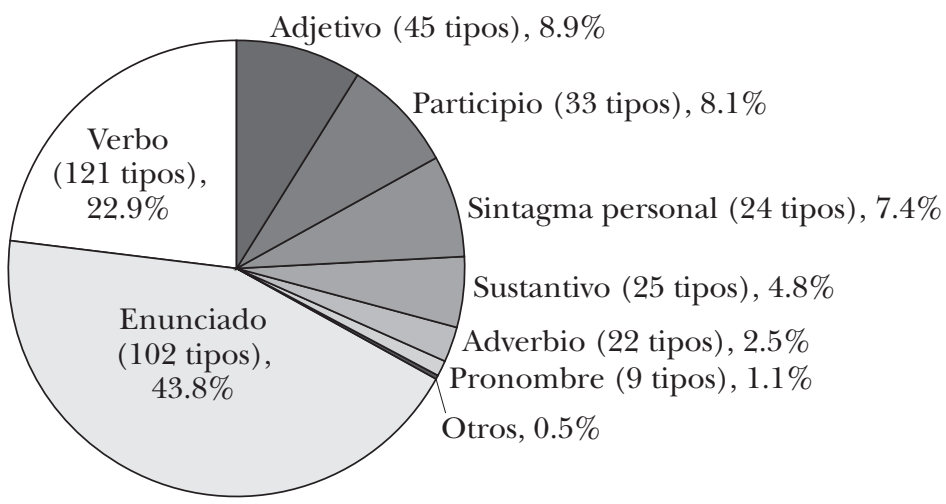

Se sabe que la función de modificación del verbo de los adverbios en -mente predomina en los textos escritos a lo largo de la diacronía de la lengua española (Company 2014). Se trata de la función nuclear de la que arrancan los procesos de poli- 
funcionalidad y polisemia. Según se observa en el Gráfico 6, este tipo pasa al segundo rango en el habla formal documentado en C-Oral-Rom, al reunir un 22.9\% de los ejemplos. Con el $43.8 \%$, los adverbios enunciativos ${ }^{10}$ predominan claramente. De ello se infiere que en la comunicación oral formal se prefieren los adverbios enunciativos, que sirven, por lo general, para determinar el punto de vista subjetivo del hablante sobre los atributos del verbo, que tienen una función descriptiva dentro del contenido proposicional. Los adverbios en -mente de cuantificación objetiva y subjetiva (= intensificación/ mitigación) ocupan el tercer lugar, ya que, desde esta perspectiva, podemos integrar en una misma categoría los atributos de adjetivos y de adverbios (11.4\%), sin hablar de los participios, en los que puede predominar la función verbal o la adjetival $(8.1 \%)$. Estos últimos comparten con los adjetivos y adverbios la tendencia, muy marcada, de anteponer el modificador a la unidad modificada, como en enormemente cansado o típicamente mexicano. Desde este punto de vista, el grupo aglomerado de modificadores de adjetivos, adverbios y participios ocupa el 19.5\% de los casos. El Gráfico 7 reproduce las frecuencias de los tipos de adverbio en el habla informal:

\section{GRÁFICo 7}

Los adverbios en -mente según las unidades modificadas (registro informal)

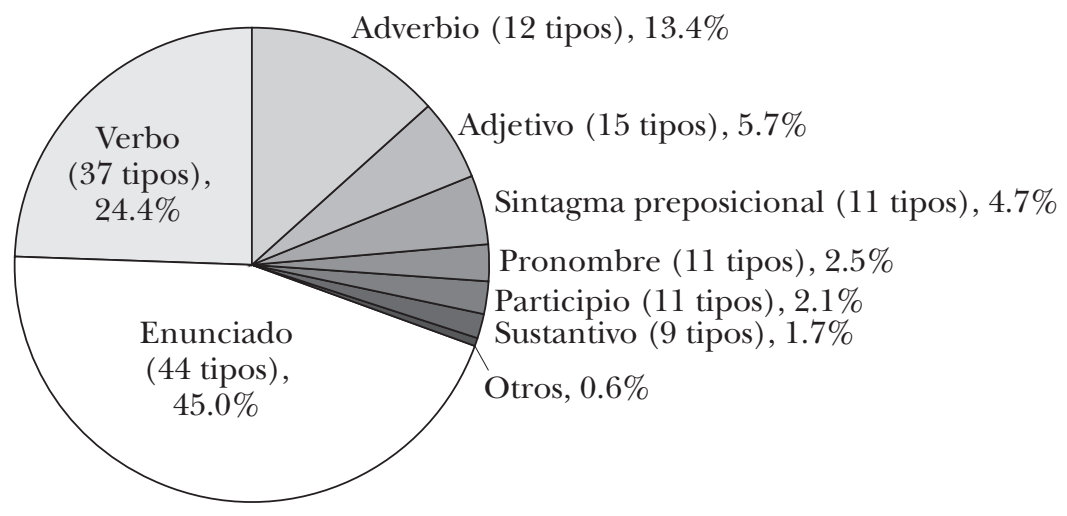

${ }^{10}$ Usamos el término adverbio enunciativo para abarcar lo que se suele diferenciar en los estudios especializados (adverbios de frase, epistémicos, de organización del discurso, de marco, de actitud, etc.). Se justifica por su implicación en el mismo proceso de expansión a partir de la función básica de modificador verbal. 
Las proporciones de los grupos más importantes, los atributos enunciativos y verbales, son prácticamente las mismas que en el subcorpus formal. De ello se desprende que el uso de los adverbios enunciativos para elaborar los discursos en los ejes intradiscursivo y extradiscursivo (interactivo) es un requisito general del habla que caracteriza tanto la expresión formal como la informal. El cambio más pertinente, según se observa, es el aumento de la función de atributos de adjetivos y adverbios, que pasa del $11.1 \%$ en el habla formal al $19.1 \%$ en el habla informal, probablemente a causa del mayor grado de emotividad de la comunicación coloquial, que se sirve de los cuantificadores para la intensificación enérgica, la mitigación, la provocación divertida, etc. Consecuentemente, la diferencia más significativa que se observa en el uso de los adverbios en -mente en los registros formal e informal es el mayor peso relativo de las funciones emocionales de intensificación y mitigación en el registro informal. La escasa frecuencia de los participios impide que el grupo aglomerado de modificadores de adjetivos, adverbios y participios (21.2\%) alcance la frecuencia de los modificadores del verbo (24.4\%).

\section{Las funciones sintácticas peninsulares frente al uso americano}

La marca morfológica -mente ha facilitado la comparación entre Europa y América en apartados precedentes. La situación se complica en esta sección y siguientes con la subcategorización sintáctica, semántica y pragmática que llevan a cabo los estudios de distintos autores. En este sentido, los resultados que se presentan a continuación son tentativos.

En su estudio sobre el uso de los adverbios en -mente en el habla culta y en la popular de la Ciudad de México, Arjona Iglesias (1991, p. 40) distingue nueve tipos de esta clase de palabras:

(A1) adverbios que modifican el verbo;

(A2) adverbios que modifican un elemento en función adjetiva;

(A3) adverbios que modifican un elemento en función adverbial;

(A4) adverbios que modifican un elemento en función sustantiva;

(A5) adverbios que funcionan como modificadores oracionales;

(A6) adverbios que funcionan como prooraciones;

(A7) adverbios que funcionan como nexos;

(A8) adverbios que se emplean como muletillas;

(A9) adverbios que equivalen a "por ejemplo". 
La autora advierte que su clasificación del habla popular coincide con la del habla culta de Vigueras Ávila, excepto por la modificación sustantiva, ausente en la clasificación de esta última autora (p. 39, n. 15). Sin embargo, le parece que los cinco ejemplares sin clasificar en Vigueras Ávila se corresponden con la modificación sustantiva. Integramos este dato en los cálculos que damos a continuación, aunque las discrepancias considerables en este campo funcional nos hacen pensar que no se trata de clasificaciones equivalentes. En todo caso, con cinco ejemplares se trata de un sector de menor importancia.

Si bien la comparación de sus datos con los de C-Oral-Rom no puede ser objetiva sin sujetar los ejemplos individualmente a los mismos criterios de clasificación, parece posible reunir los grupos (A5, A6, A7, A8, A9) en el de los adverbios enunciativos, ya que no es nuestro propósito analizar en detalle la elaboración del discurso. De esta forma, se obtiene un esquema comparable al de las funciones K1, K2, K3, K4 y K5, apuntadas supra:

(AA1) adverbios que modifican el verbo;

(AA2) adverbios que modifican un adjetivo;

(AA3) adverbios que modifican un adverbio;

(AA4) adverbios que modifican un sustantivo;

(AA5) adverbios que modifican el enunciado.

Eliminando algunos errores de cálculo y de redondeo en Arjona Iglesias (1991), se obtienen las cifras documentadas en los Gráficos 8 y 9. Las cifras son comparables entre los dos corpus mexicanos, cada uno representado por 17 horas de grabación en condiciones análogas.

No sería lícito comparar sin más los datos de los Gráfico 8 y 9 con los de los Gráficos 6 y 7, no solamente por las diferencias de sistematización. El problema principal es que los criterios "culto/ popular" no coinciden con los criterios "formal/ informal" aplicados en el corpus peninsular. Se sabe que los datos del habla culta son bastante formales, pero los del habla popular se componen de información grabada en secreto y en público. Se confirma, sin embargo, que la repartición interna de las funciones AA1-5 es semejante tanto en la comparación del habla culta con la popular, como también entre éstas y los datos orales formales e informales del corpus C-Oral-Rom peninsular.

Es llamativa la frecuencia de los modificadores del verbo en los corpus americanos, superior a la que registra el europeo. 


\section{GrÁFICO 8}

Frecuencia relativa en porcentaje de los adverbios en -mente en el habla popular de México según la unidad modificada

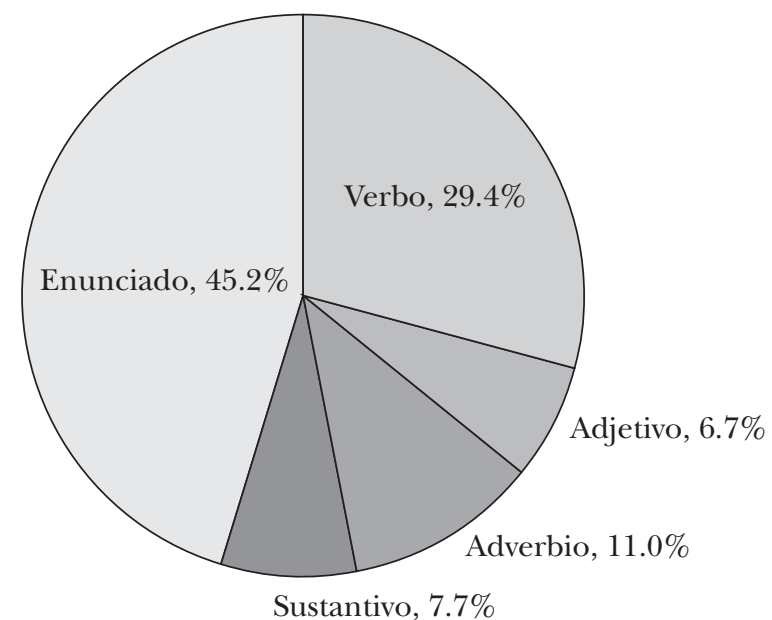

Sustantivo, $7.7 \%$

\section{GRÁFICo 9}

Frecuencia relativa en porcentaje de los adverbios en -mente en el habla culta de México según la unidad modificada

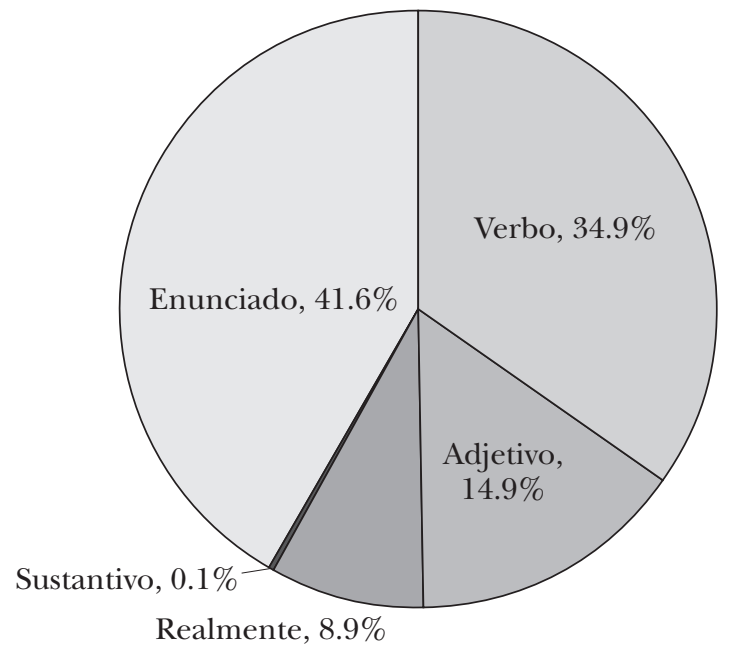

Nueva Revista de Filología Hispánica (NRFH), LXVI, 2018, núm. 1, 3-42

ISSN 0185-0121; e-ISSN 2448-6558; DOI: 10.24201/nrfh.v66i1.3391 
Podríamos eventualmente relacionar este fenómeno con una menor penetración diacrónica de las funciones discursivas de adverbios en -mente en la variedad mexicana. Si es cierto, en efecto, que las funciones discursivas y cuantitativas se desarrollaron diacrónicamente a partir de la función base de modificación del verbo (v.gr. curiosamente, naturalmente), podríamos pensar que Europa representa una etapa progresiva, marcada por una mayor penetración de las funciones discursivas. Sin embargo, habría que confirmar esta hipótesis con datos mejor controlados.

En conclusión, podemos afirmar que el peso relativo de las funciones sintácticas llega a equipararse en las hablas formal e informal del corpus peninsular C-Oral-Rom y, cum grano salis, también en los corpus mexicanos. A diferencia del uso peninsular, el habla mexicana conserva más claramente la función primaria de modificación del verbo.

\section{LA CLASIFICACIÓN SEMÁNTICO-PRAGMÁTICA}

\section{Las funciones semántico-pragmáticas}

El hecho de escoger la escritura como fuente de documentación explica la predominancia en las gramáticas de los adverbios del Tipo B (en -mente) en detrimento de los Tipos A y C. Con su arquitectura compleja de tipos de textos y de tradiciones discursivas, marcada por una función de comunicación que transgrede el espacio y el tiempo que separan a los que escriben y leen, la escritura necesita una diferenciación mayor, y sobre todo más explícita ${ }^{11}$, de las funciones adverbiales que sirven para describir y situar con precisión lo dicho por escrito. En efecto, en las gramáticas, los adverbios en -mentese emplean para ilustrar una larga serie de funciones, tales las de tiempo, manera, comentario, evaluación subjetiva, punto de vista, grado (intensidad), focalización, reformulación, respuesta y confirmación (cf. Kovacci 1999). Sería difícil usar el mismo grado de diferenciación semántico-pragmático en la lengua hablada. Por eso, hemos optado por distinguir solamente nueve funciones:

11 En la oralidad informal, la riqueza suele ser de tipo inferencial, según se desprende del alto grado de polisemia y polifuncionalidad de los marcadores del discurso. 
(1) tiempo (v.gr. actualmente);

(2) manera;

(3) evaluación enunciativa subjetiva, punto de vista, marco;

(4) grado, intensidad (4+), mitigación (4-), aproximación (4) ${ }^{12}$;

(5) conexión, enumeración;

(6) enfoque, especificación;

(7) respuesta afirmativa, negativa, evaluativa en general (v.gr. probablemente);

(8) lugar (v.gr. localmente);

(9) frecuencia.

El listado contiene algunos ejemplos que se pueden citar sin contexto. Las demás funciones se tratarán en lo que sigue.

La clasificación de los ejemplos no pudo realizarse con correspondencias del tipo "una ocurrencia - una función”. El desarrollo diacrónico de nuevas funciones a partir de la función de modificación del verbo conlleva naturalmente la coexistencia transparente de la antigua y la nueva función, por lo menos durante algún tiempo. Muchos adverbios en -mente acumulan varias funciones semántico-pragmáticas en un contexto dado. Para tenerlo en cuenta, admitimos hasta tres funciones por cada ejemplo, separados en columnas en una hoja de cálculo ${ }^{13}$. En lugar de ordenar las columnas según las funciones -v.gr. primera columna (función semántica); segunda (función discursiva); tercera (función pragmática)-, hemos intentado colocar en la primera columna la función predominante. Así, en el ejemplo (a) predomina la función de respuesta de efectivamente (7), necesariamente evaluativa (3), y comporta, además, cierto énfasis (4+). En el ejemplo (b), en cambio, la evaluación epistémica (3) predomina sobre lo que efectivamente podría conllevar como respuesta, dentro del discurso (7), manteniendo cierto énfasis $(4+)$, no muy fuerte.

(a) / esto está claro/JAV: $[<]<$ efectivamente $>/ /$

(b) $/[<]<$ y aplica $[/ / /]$ se considera vehículo $>+$ efectivamente //

12 Véase la discusión de los términos en Schneider 2016.

13 El fichero con los ejemplos y su clasificación es públicamente accesible en la página web del grupo de investigación (véase nota 2). 
En otro ejemplo, generalmente combina la evaluación (3) con la frecuencia (9) y la aproximación (4):

(c) / durante este periodo de tiempo/ generalmente es cuando se hacen los reconocimientos/y/ otras pruebas judiciales//

En el ejemplo (d), finalmente combina el orden de secuencia (5), que puede referirse al evento o, en otras ocasiones, a la ordenación del discurso, con la localización en el tiempo (1):

(d) // finalmente se crearán/ trescientos veinticinco mil puestos de trabajo netos/

En el ejemplo siguiente, normalmente traduce, en primer lugar, una opinión del locutor (3), en segundo, una frecuencia de ocurrencia (9) en términos de aproximación (4):

(e) // es decir normalmente lo que ocurre / es que / el [/] al mal / traductor.../

La combinación de las funciones de frecuencia (9), de tiempo (1) y de manera (2) se produce a menudo, como en (f) (9, $1,2)$ y en $(\mathrm{g})(9,1)$ :

(f) / podía elevar / diariamente / diecisiete mil litros del agua del Tajo /

(g) // trabajar en mi equipo / como lo estoy haciendo habitualmente /

En algunos casos, la clasificación no resulta completamente satisfactoria. Así, en ciertos ejemplos con prácticamente, la mitigación (4-) se combina con énfasis contextual, que justificaría la clasificación algo contradictoria $(4+)$ :

(h) / ...son tantísimas especies / que hablar/\&eh/ de algo/ general de ellos/ pues es/ prácticamente imposible/

Por su peso fonético, con dos acentos (prácticaménte), los adverbios en -mente tienden a ser llamativos por naturaleza, efecto que incrementa cuando se usan antepuestos y se combinan, además, con un adjetivo de valoración enfática, como en el ejemplo (h). Tales factores solamente podrían tenerse en cuen- 
ta con una clasificación mucho más fina, con criterios como la posición sintáctica, la entonación, el contexto, por sólo mencionar algunos. Creemos, sin embargo, que tales problemas de clasificación no afectan de forma significativa las tendencias observables a partir de nuestro esquema de clasificación. En todo caso, la posibilidad de combinar hasta tres funciones nos ha permitido reducir a cero los casos sin clasificar. Evitamos, de esta forma, uno de los problemas perceptibles en las gramáticas que tienden a clasificar los lexemas bajo una sola función. Esto sólo es posible mediante la ilustración de las funciones con lexemas y ejemplos seleccionados según criterios de prototipicidad. Un análisis objetivo tiene que proceder de forma más diferenciada.

Como es obvio, ningún tipo de clasificación cualitativa está al margen del sesgo de la subjetividad. Para garantizar un mínimo de control, primero hemos clasificado los ejemplos, cada uno por su lado; después, hemos comparado los resultados y analizado conjuntamente los casos de divergencia. Además, el efecto de frecuencia que nos garantizó el trabajar con solamente nueve categorías semántico-pragmáticas ha reducido el peso de posibles clasificaciones problemáticas a la hora de cuantificar. Finalmente, si por un lado la posibilidad de combinar hasta tres funciones puede conllevar problemas de jerarquización (¿cuál es la función principal?), por otro, esta técnica permite tener en cuenta todas las funciones combinadas, al menos en uno de los niveles de la jerarquía.

\section{Las principales funciones semántico-pragmáticas}

El Gráfico 10 indica las frecuencias relativas de las funciones semántico-pragmáticas principales respecto al tamaño del corpus total y de los subcorpus formal e informal. De esta forma, los datos sólo indican las proporciones de uso dentro del corpus, eliminando las diferencias de frecuencia, que, como se ha dicho, son tres veces mayores en el corpus formal que en el informal.

Se confirma nuevamente que la repartición de las funciones es básicamente un hecho del habla en general y no de los registros formal e informal, que poco se distinguen al respecto. Los perfiles son prácticamente idénticos. Se puede hacer hincapié en tendencias menores, como la preferencia de los textos forma- 


\section{GRÁFICO 10}

Frecuencia relativa en porcentaje de las funciones semánticas primarias

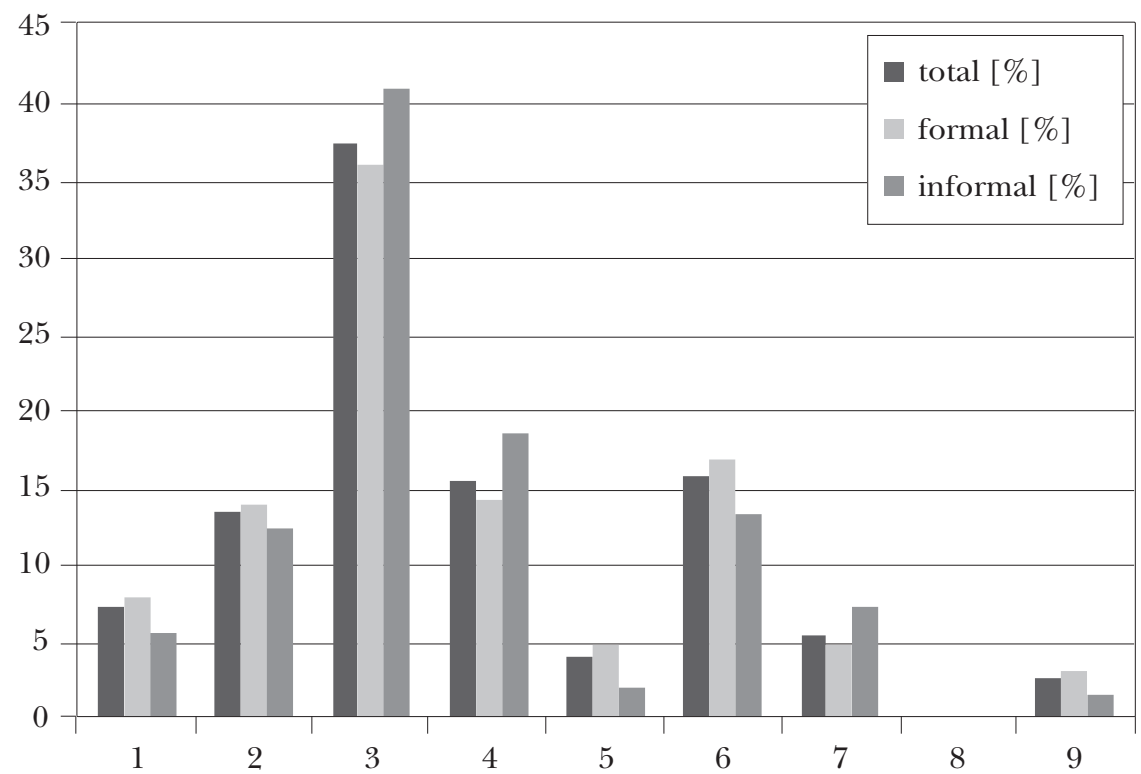

les a elaborar más las funciones que sitúan $(1,9)$, estructuran (5) o especifican (6) lo dicho, o la de los textos informales a relacionarse con la subjetividad (4), con la intensificación/ mitigación (4) y lo dialógico (7). Es posible decir que el esfuerzo retórico en los textos formales se dedica más a situar, focalizar y especificar lo dicho, en tanto que en los textos informales el mismo esfuerzo tiende a manifestarse en el campo de la subjetividad emocional. Sin embargo, repitámoslo, estas diferencias son menores.

El Gráfico 11 considera aparte las funciones semánticopragmáticas de los diez adverbios más frecuentes. De él se desprende muy claramente que el habla prefiere las funciones de evaluación subjetiva (3) y de intensificación/ mitigación (4) en detrimento de la función de manera (2). Conforme a lo que ya hemos visto, esta última prevalece en los textos escritos. Según Ramat y Ricca (1994, pp. 317-319) se trata de una tendencia que se observa por medio de las lenguas. 
Frecuencia relativa en porcentaje de las funciones semántico-pragmáticas en los diez adverbios más frecuentes (corpus total)

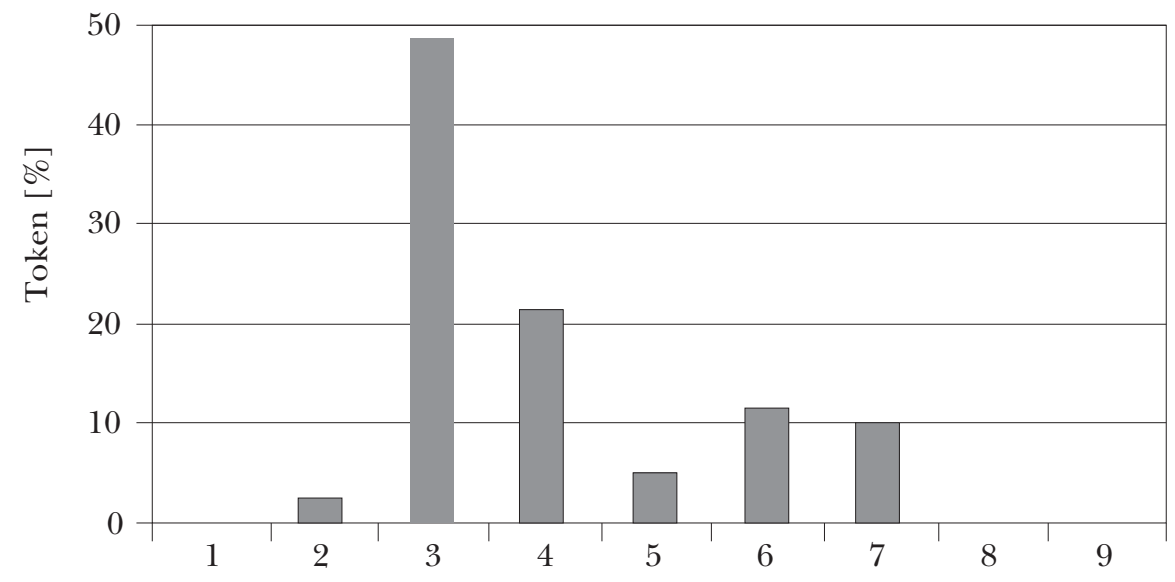

El cúmulo de las funciones semántico-pragmáticas

Resulta interesante analizar las funciones semántico-pragmáticas combinadas. El Gráfico 12 señala las combinaciones que se derivan del análisis de las unidades más frecuentes. Las cifras de la línea inferior se corresponden con las nueve categorías detalladas anteriormente en el apartado "Las funciones semánticopragmáticas".

Hay tres funciones que no se realizan del todo con las unidades más frecuentes: las de tiempo (1) y lugar $(8)^{14}$, e incluso la función básica de manera (2). En los restantes casos, el hecho de combinarse entre ellos prevalece claramente. Se trata, pues, de unidades polifuncionales. La combinación que más destaca es la de evaluación subjetiva y marco (3) con la intensidad (4). Éstas son dos de las tres funciones que se efectúan sin combinarse con otras (como también 6/0/0). Entre todas ellas, la intensidad es la única que se usa con mayor frecuencia. La eva-

${ }^{14}$ Esta última tampoco se encuentra en el corpus completo. Un ejemplo sería localmente. 
GRÁFICO 12

Frecuencia absoluta de las combinaciones de funciones en los diez adverbios más frecuentes (corpus total)

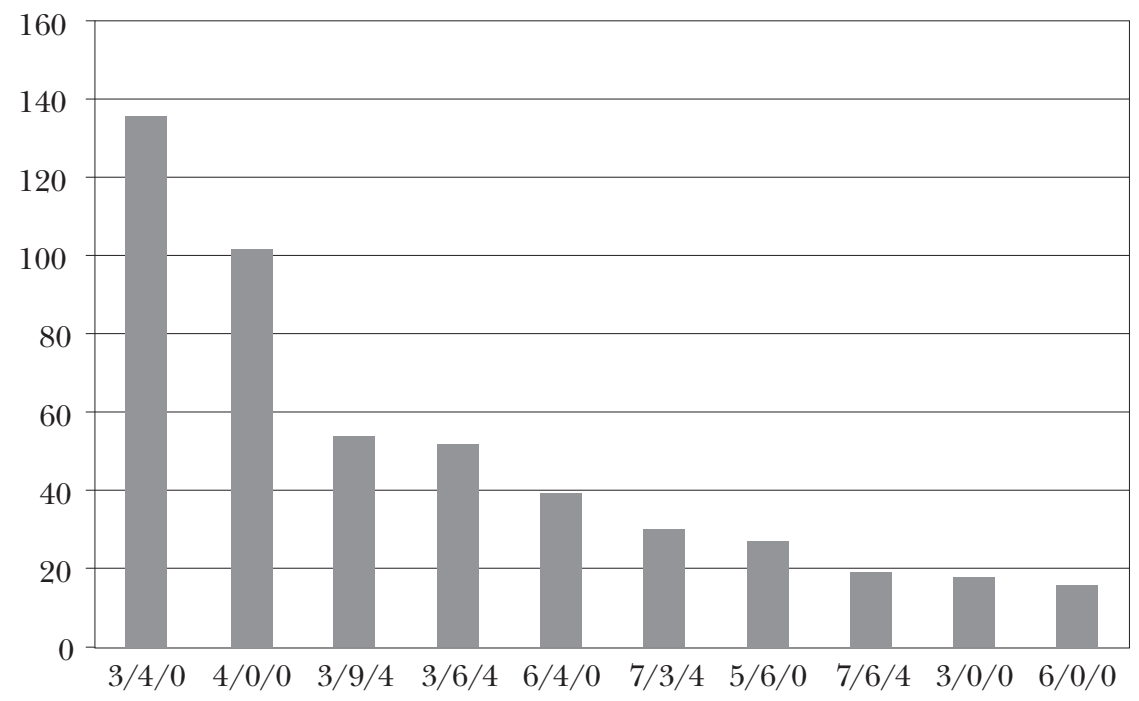

luación subjetiva (3) y el enfoque (6), sin ninguna otra categoría incorporada, se ubican al final de la escala de frecuencias. La preferencia por la combinación de evaluación subjetiva (3), frecuencia (9) e intensidad (4) ocupa el tercer lugar, casi con la misma frecuencia que la combinación de evaluación subjetiva (3) con enfoque (6) e intensidad (4). Asimismo, enfoque e intensidad (6-4) representan otra característica notable.

Véanse ahora en los Gráficos 13 y 14 las combinaciones observables en todos los adverbios del corpus, separando, sin embargo, los registros informal y formal. Si dejamos de lado la frecuencia mayor en los textos formales, ya analizada, la combinación evaluación-intensidad (3-4) se evidencia como característica general en los dos registros. Ello refleja la alta frecuencia token de los adverbios con funciones discursivas. Lo que cambia respecto del Gráfico 11 es la mayor penetración de las unidades monofuncionales y, especialmente, las de evaluación subjetiva (3) y, ahora sí, de manera (2). El carácter monofuncional se observa también en las categorías de intensidad (4), tiempo (1) y enfoque (6). Los usos monofuncionales de evaluación subjetiva (3) y de manera (2) ocupan el segundo y tercer lugares en la escala de frecuencias. El hecho de que sus rangos respectivos se 


\section{GRÁFICO 13}

Frecuencia absoluta de las combinaciones de funciones en todos los adverbios del corpus (registro informal)

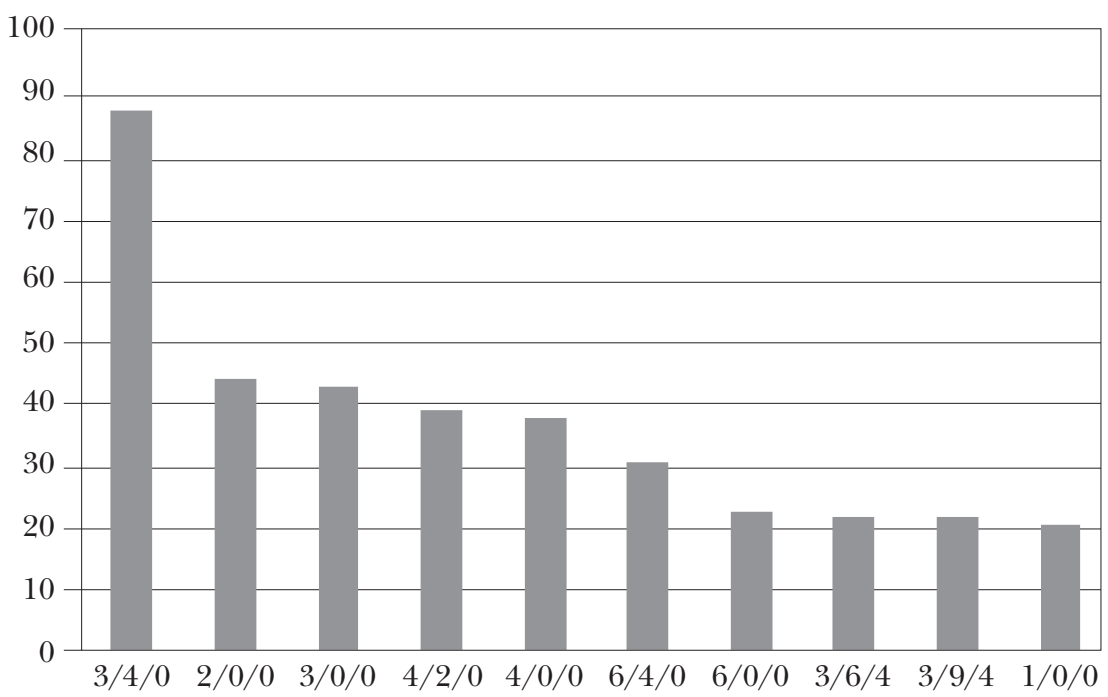

\section{GrÁFICO 14}

Frecuencia absoluta de las combinaciones de funciones en todos los adverbios del corpus (registro formal)

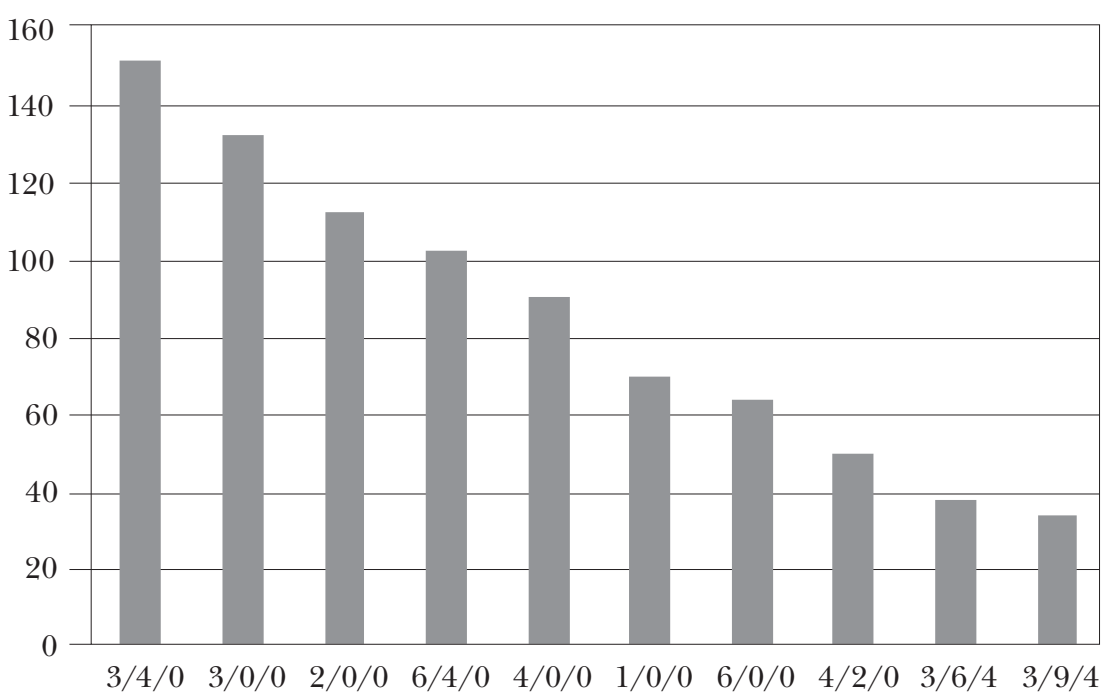

Nueva Revista de Filología Hispánica (NRFH), LXVI, 2018, núm. 1, 3-42

ISSN 0185-0121; e-ISSN 2448-6558; DOI: 10.24201/nrfh.v66i1.3391 
inviertan en los registros formal e informal podría relacionarse con el carácter más argumentativo de los textos formales.

LA FRECUENCIA DE LOS ADVERBIOS EN -MENTE SEGÚN EL TIPO DE COMUNICACIÓN / TEXTO EN EL HABLA FORMAL E INFORMAL

\section{Los textos formales}

El análisis de los subgrupos del registro formal pone de manifiesto que la relativa homogeneidad de las archicategorías media y natural context en el Gráfico 2 es un efecto de superficie. Y así es, según la información registrada en el Gráfico 15, que muestra una categoría media bastante heterogénea en lo que atañe al uso de los adverbios en -mente:

\section{GRÁFICO 15}

Frecuencia relativa en porcentaje de los adverbios en -mente en la subcategoría media (registro formal)

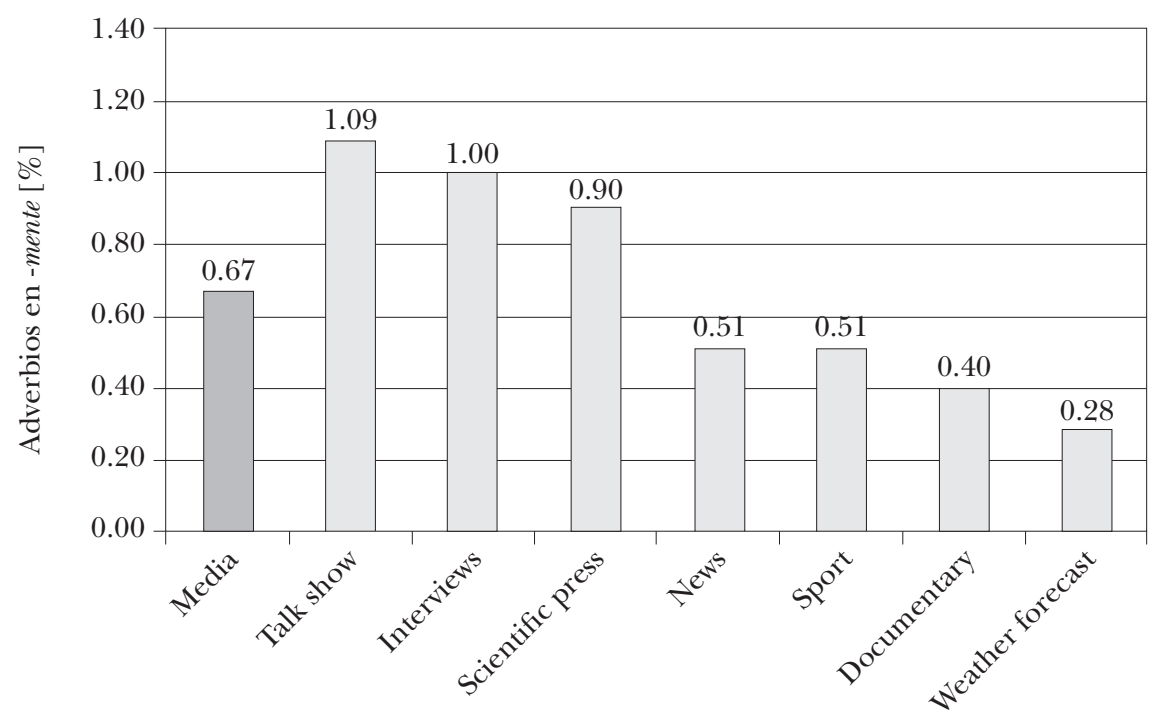

Según estos datos, el carácter dialógico (talk show, interview) y el grado de elaboración (scientific press) favorecen el uso de los adverbios, mientras que la brevedad (news, weather forecast) y la objetividad descriptiva (documentary) reducen la probabilidad de su uso. Del conjunto de rasgos observables en las siete subcate- 
gorías de la categoría formal de los media se colige que un mayor grado de preparación y elaboración favorece el empleo de los adverbios en -mente, con tal de que no intervengan imperativos que reduzcan la expresión a los contenidos proposicionales y obliguen a la brevedad, como sucede en los news y los forecasts.

En la subcategoría natural context, la repartición es más equitativa, a excepción de los textos jurídicos, que recurren con predilección a este tipo de adverbios:

\section{GrÁFICO 16}

Frecuencia relativa en porcentaje de los adverbios en -mente en la subcategoría natural context (registro formal)

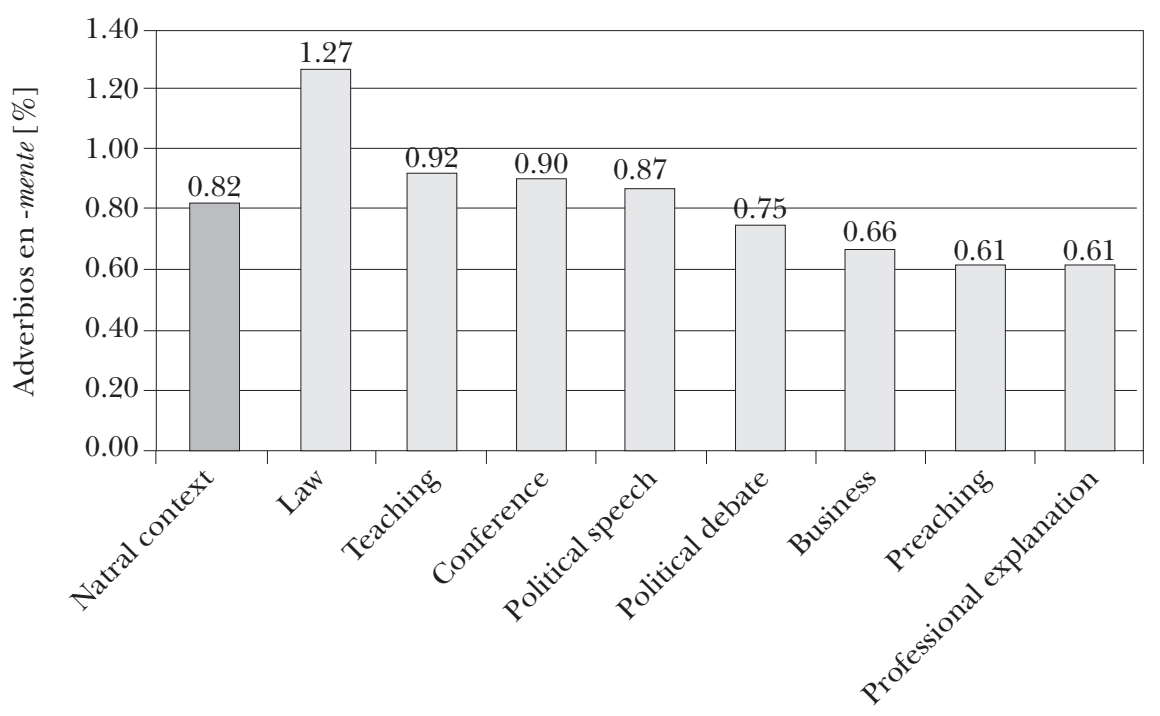

Según los promedios generales que muestran el Gráfico 15 (0.67) y el Gráfico $16(0.82)$, la frecuencia es más alta en este último. Una posible explicación sería la ausencia de textos descriptivos breves en la categoría natural context. Notemos finalmente que Kraschl (2008, p. 41) observa diferencias considerables entre los textos jurídicos.

\section{Los textos informales}

La frecuencia de adverbios en -mente en la subcategoría de la comunicación en público (public) varía según el tipo de comunicación: 
Gráfico 17

Frecuencia relativa en porcentaje de los adverbios en -mente en la subcategoría public (registro informal)

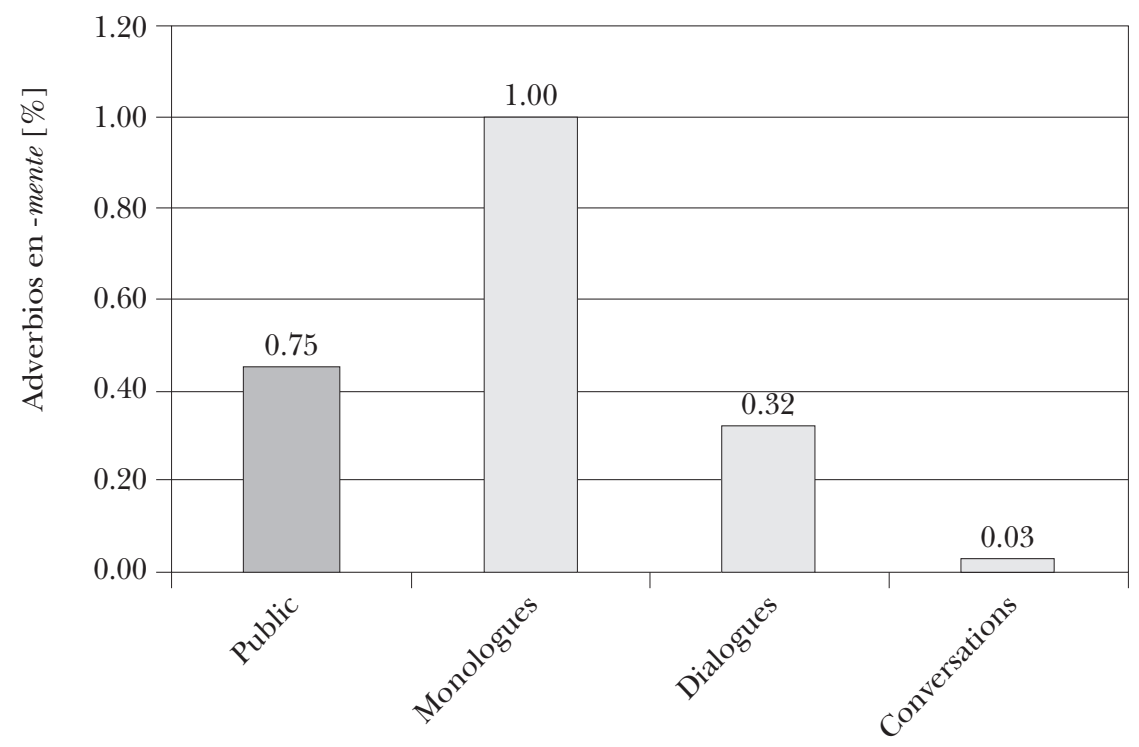

A diferencia de los textos de la subcategoría media en el registro formal (Gráfico 15), los adverbios en -mente no se usan con mayor frecuencia en los discursos interactivos dialogales o conversacionales (Gráfico 17). Las partes del corpus, correspondientes a los grupos dialogal (dos grabaciones) y conversacional (dos grabaciones), son muy reducidas, en comparación con el grupo monologal (dieciocho grabaciones). Por eso sería prematuro sacar conclusiones definitivas de las discrepancias.

En la subcategoría de las comunicaciones informales entre familiares y amigos (family private), la frecuencia relativa de los adverbios en -mente es del $0.22 \%$ (véase Gráfico 18), es decir, no llega a la mitad de la frecuencia de la subcategoría public (cf. Gráfico 17).

Se confirma la misma tendencia a usar menos los adverbios en -mente en las comunicaciones interactivas que en las monologales. La frecuencia más baja se observa en las llamadas telefónicas $(0.13 \%)$, incluidas en el grupo private conversations.

Resulta llamativo que los adverbios en -mente, que sirven en gran parte para organizar el discurso, sean menos frecuentes en los textos interactivos, a diferencia del subcorpus formal. No 
GrÁFICO 18

Frecuencia relativa en porcentaje de los adverbios en -mente en la subcategoría family private (registro informal)

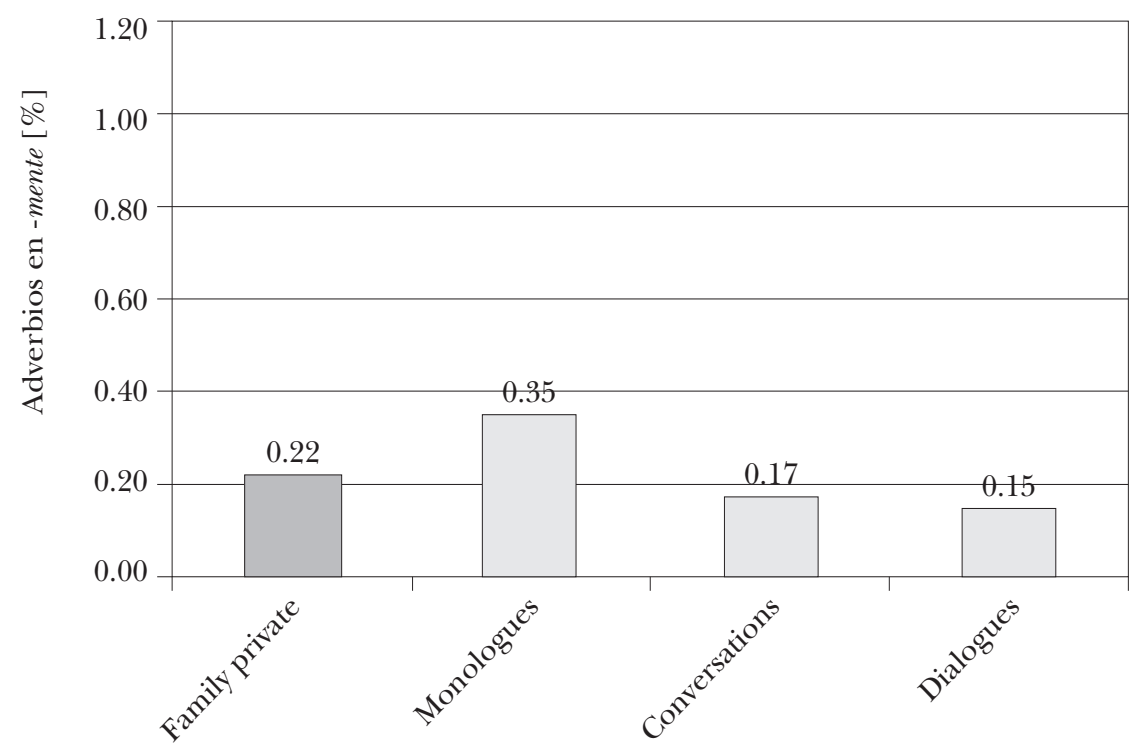

obstante, es posible que la informalidad favorezca el uso de los marcadores discursivos del tipo bueno, claro, igual, total, por cierto, etc., en detrimento de los adverbios en -mente, más característicos de los registros formales. Habría que emprender un estudio onomasiológico (cf. supra), con el objetivo de determinar cuál es la frecuencia relativa de los adverbios en -mente frente a soluciones alternativas dentro de una misma función discursiva, como en las respuestas, v.gr. claro/ claramente, seguro/ seguramente, sí, efectivamente, etcétera.

Para el propósito de la presente investigación, cabe resaltar que el tipo de texto (tipo de discurso) es un factor relevante para el uso de los adverbios en -mente. Por eso, cabría continuar la investigación respecto a los tipos de texto con sus posibles tradiciones discursivas. Sin embargo, tampoco se debe pasar por alto el hecho de que un solo texto puede reunir usos pragmático-contextuales (o situacionales) muy diversos. Además, hemos observado en nuestros datos que las diferencias individuales pueden ser de consideración en un mismo tipo de texto. 


\section{Conclusión}

En el trabajo se propuso investigar el empleo de los adverbios en -mente en el C-Oral-Rom, corpus oral del español peninsular que permite analizar las variables de formalidad-informalidad, nivel educativo y tipo de texto. Aprovechamos la existencia de datos mexicanos, hasta cierto punto comparables, para añadir una perspectiva contrastiva. Partimos de la hipótesis diacrónica formulada por Company (2012, 2014), según la cual los adverbios en -mente, en su gran mayoría, son cultismos ${ }^{15}$ cuya propagación diacrónica fue catalizada por el proceso de implementación de la escritura. De ser así, supusimos que la sincronía variacional todavía llevaría las marcas de la tradición culta. Esta hipótesis se vio plenamente confirmada. Tanto en la Ciudad de México como en Europa (esencialmente Madrid), la frecuencia de uso de los adverbios en -mente es tres veces superior en los textos con mayor influencia de la tradición escrita. Se observó, además, que el control social favorece la utilización de este tipo de adverbios. En efecto, en los datos que arrojan los registros informales, la frecuencia de uso se incrementa aún más cuando la situación comunicativa se desenvuelve en un entorno público, pues el empleo de los adverbios llega a ser catorce veces más frecuente cuando los hablantes saben que están siendo grabados. El grado de escolaridad influye también en el uso de los adverbios en -mente, ya que de nuevo su aparición es tres veces mayor en los hablantes más cultos (C-Oral-Rom). Esto no implica que todos los hablantes cultos los usen con mayor frecuencia, sino que todos los hablantes que muestran su predilección por este tipo de adverbios pertenecen al estrato más culto. En otras palabras, parece que unos relacionan su uso con una cuidada forma de hablar.

Los adverbios más frecuentes, que suelen servir para presentar el discurso de manera subjetiva y para organizarlo, son exactamente los mismos en los textos formales e informales. Ello muestra que se trata de una propiedad general del habla que no cambia según el registro. Sin embargo, la frecuencia type pone en evidencia un uso más diferenciado de estas unidades descriptivas en los textos formales. A diferencia de la tradición

15 Ante conceptos tradicionales como préstamo (culto) o ingl. learned lexicon, que incluyen una perspectiva etimológica de origen, el concepto de $\mathrm{cul}$ tismo alude a una preferencia por el habla culta. 
escrita, en que prevalece la función sintáctica de modificador del verbo (de la que arrancan los procesos diacrónicos de gramaticalización y discursivización), los adverbios con funciones de presentación subjetiva y de organización del discurso ocupan el primer rango en el corpus oral, posición que, aparentemente, desciende en México, donde la proporción de la modificación del verbo es algo superior. Para determinarlo con mejor criterio, habría que adoptar una perspectiva onomasiológica que incluyera otros tipos de adverbios, como los adjetivos adverbiales o las frases preposicionales.

Al final de su trabajo sobre la fuerte implicación de los adverbios en -mente en el tramado de los enunciados, Company (en prensa) formula una hipótesis muy sugerente, según la cual la vinculación de los adverbios en -mente con los textos escritos podría ser la consecuencia de esta propiedad sintáctico-textual. No las tradiciones de la escritura, sino los mismos adverbios estarían imponiendo su propio uso en textos complejos. Sin embargo, esto significaría que las lenguas germánicas y el rumano, que usan los adjetivos adverbiales, deberían asociar sus adverbios a contextos menos complejos o desarrollar culturas de menor complejidad textual. Va en contra de la intuición, desde el punto de vista traductológico, por ejemplo. Pensamos, pues, que el hecho empírico incontestable de la integración en contextos más complejos, que Company sacó a la luz, debe de ser la consecuencia de su uso por la tradición escrita. Nuestro corpus aporta un elemento interesante al respecto. Desde el punto de vista de la tipología textual, llama la atención que los adverbios en -mente se usen más en los textos monologales que en los dialogales. Este hecho se relaciona con una observación diacrónica en Hummel (2014, en prensa a y b), según la cual los adverbios en -mente se imponen en el proceso de implementación del español moderno durante el siglo XVII, en que el estilo moderno, fluido y elegante, según el modelo francés, se impone sobre el estilo barroco, altisonante y parentético. El estilo nuevo emplea sobre todo los adverbios en -mente para apoyar la fluidez del acto de escribir y dar al discurso un cariz narrativo, que todavía se advierte cuando contrastamos ciertamente con cierto, claramente con claro, etc. Recuérdese el criterio a veces utilizado para verificar la elegancia del estilo: el poder leer en voz alta, sin parar, a no ser que se llegue al final de la frase. Es un control de fluidez. A diferencia de este modelo, cuando se emplean los marcadores discursivos orales se los suele destacar mediante las pausas 
y la entonación, muchas veces con el propósito de interrumpir, a veces abruptamente. En este sentido, Schneider (2013) observa un fenómeno complementario: los marcadores discursivos parentéticos se usan más en los textos dialogales que en los monologales. No es que los adverbios en -mente con funciones discursivas no se destaquen en los textos descritos, sino que su preponderancia se matiza por el hecho de que los propios adverbios adquieren una entonación casi frástica.

En lo que toca a los problemas metodológicos de clasificación de los textos según los criterios de (in)formalidad y de comparación de corpus con estructuras internas no directamente compatibles, se verificó que ello no impide, en este trabajo concreto, que se desprendan las tendencias más relevantes. Los análisis según los ejes de formalidad/ informalidad y de habla culta/ popular proporcionaron resultados coherentes, también con respecto a otros trabajos mencionados en la bibliografía.

\section{REFERENCIAS}

Arjona Iglesias, Marina 1991. "Los adverbios terminados en -mente", en Estudios sintácticos sobre el habla popular mexicana. Ed. Marina Arjona Iglesias, Universidad Nacional Autónoma de México, México, pp. 25-63.

Bilger, Mireille 2004. "Quelques données sur les adverbes en -ment dans le corpus de référence de [sic] français parlé”, en Recherches sur le français parlé 18 (Autour du corpus de référence du français parlê), Publications de l'Université de Provence, Aix-en-Provence, pp. 63-81.

Briz Gómez, Antonio 1998. El español coloquial en la conversación. Esbozo de pragmagramática, Ariel, Barcelona.

Company Company, Concepción 2012. "Condicionamientos textuales en la evolución de los adverbios en -mente", Revista de Filología Española, 92, 1 , pp. 9-42.

Company Company, Concepción 2014. "Los adverbios en -mente", en Sintaxis histórica de la lengua española. Tercera parte: Adverbios, preposiciones y conjunciones. Relaciones interoracionales. Dir. C. Company, Universidad Nacional Autónoma de México-Fondo de Cultura Económica, México, t. 1 , pp. $459-611$.

Company Company, Concepción en prensa. "Adverbial adjectives and -mente adverbs face to face. Diachronic evidence from Spanish”, en The adjective adverb interface in Romance. Eds. Martin Hummel \& Salvador Valera.

CREA = Real Academia Española. Corpus de Referencia del Español Actual, http:/ / corpus.rae.es/creanet.html [consultado en marzo de 2009].

Cresti, Emanuela \& Massimo Moneglia (eds.) 2005. G-ORAL-ROM: Integrated reference corpora for spoken Romance language, J. Benjamins, Amsterdam-Philadelphia. 
CSCM = Pedro Martín Butragueño y Yolanda Lastra (coords.) 2011-2015. Corpus sociolingüistico de la Ciudad de México, El Colegio de México, México.

Egea, Esteban Rafael 1993. "Restricciones lexicológicas en el uso de los adverbios en -mente", en La formación de palabras. Ed. Soledad Varela, Taurus, Madrid, pp. 282-299.

Garcés Gómez, María Pilar 1998. "Formas adjetivas con función adverbial en español”, Romanistisches Jahrbuch, 49, pp. 283-306.

Hummel, Martin 2002. "Considerações sobre os tipos Ela fala esquisito e Ela chega cansada no português coloquial e literário do Brasil e de Portugal”, Confluência, 24, pp. 43-70.

Hummel, Martin 2012. Polifuncionalidad, polisemia y estrategias retóricas. Los signos discursivos con base atributiva entre oralidad y escritura [acerca del uso de bueno, claro, total, realmente, etc.], De Gruyter, Berlin-Boston.

Hummel, Martin 2013. "Sincronía y diacronía de los llamados adjetivos adverbializados y de los adverbios en -mente", Anuario de Letras. Lingüistica y Filología, 1, 2, pp. 215-281.

Hummel, Martin 2013a. "Attribution in Romance: Reconstructing the oral and written tradition”, Folia Linguistica Historica, 34, pp. 1-42.

Hummel, Martin 2014. "Los adjetivos adverbiales", en Sintaxis histórica de la lengua española. Tercera parte: Adverbios, preposiciones y conjunciones. Relaciones interoracionales. Dir. C. Company, Universidad Nacional Autónoma de México-Fondo de Cultura Económica, México, pp. 615-733.

Hummel, Martin 2014a. "La reconstrucción diacrónica entre oralidad y escritura. El caso de los marcadores discursivos claro, entonces y total', en Marcadores del discurso. Perspectivas y contrastes. Ed. María Marta García Negroni, Santiago Arcos, Buenos Aires, pp. 35-61.

Hummel, Martin 2014b. "The adjective-adverb interface in Romance and English”, en Adjectives in Germanic and Romance. Eds. Petra Sleeman, Freek Van de Velde \& Harry Perridon, J. Benjamins, Amsterdam-Philadelphia, pp. 35-71.

Hummel, Martin en prensa a. "Éléments d'une diachronie grammaticographique de l'adverbe français accompagnés de trois méthodes pour mesurer son effet sur l'usage", Romanische Forschungen.

Hummel, Martin en prensa b. "Romance sentence adverbs in -mente: Epistemic mitigation in synchrony and diachrony".

Koch, Peter y Wulf Oesterreicher 2007. Lengua hablada en la Romania: español, francés, italiano, Gredos, Madrid.

Kovacci, Ofelia 1999. "El adverbio", en Gramática descriptiva de la lengua española. Eds. Ignacio Bosque y Violeta Demonte, Espasa, Madrid, t. 1, pp. 705-786.

Kraschl, Carmen Therese 2008. Adverbien auf “-mente" im gesprochenen Spanisch. Eine Analyse anhand von C-ORAL-ROM, tesis, Karl-Franzens-Universität Graz.

Lara, Luis Fernando (dir.) 2010. Diccionario del español de México, El Colegio de México, México, 2 ts.

LOPE Blanch, JuAn 1986. "El concepto de prestigioy la norma lingüística del español”, en Estudios de lingüistica española, Universidad Nacional Autónoma de México, México, pp. 17-31. 
Medina Gómez, Lorena y Luisa Josefina Alarcón Neve 2013. "El adverbio de manera corto en el español formal de México”, Verba Hispánica, 21, pp. 55-74.

Rainer, Franz 1993. Spanische Wortbildungslehre, M. Niemeyer, Tübingen.

Ramat, Paolo \& Davide Ricca 1994. "Prototypical adverbs: On the scalarity/radiality of the notion of adverb", Rivista di Linguistica, 6, 2, pp. 289-326.

Rodríguez Ramalle, Teresa María 2003. La gramática de los adverbios en “-mente", Universidad Autónoma de Madrid, Madrid.

Samper Padilla, José Antonio 2014. "Cincuenta años del proyecto de estudio de la norma culta hispánica”, Lingüistica Española Actual, 36, 1, pp. 149-170.

Santos Río, Luis 2003. Diccionario de partículas, Luso-Española de Ediciones, Salamanca.

Schneider, Stefan 2013. "Clauses parenthétiques réduites et type d'interaction verbale", en Des sentiments au point de vue. Éds. Hélène Chuquet, Raluca Nita et Freiderikos Valetopoulos, Presses Universitaires, Rennes, pp. 175-194.

Schneider, Stefan 2016. "Las dimensiones de la intensificación y de la atenuación”, en Atenuación e intensificación en géneros discursivos. Eds. Marta Albelda Marco y Wiltrud Mihatsch, Iberoamericana-Vervuert, MadridFrankfurt/M. (Lingüistica Iberoamericana, 65).

Seco, Manuel, Olimpia Andrés y Gabino Ramos 1999. Diccionario del espanol actual, Aguilar, Madrid, 2 ts.

Thompson, Sandra A. \& Anthony Mulac 1991. "A quantitative perspective on the grammaticization of epistemic parentheticals in English", en Approaches to grammaticalization. T. 2: Focus on types of grammatical markers. Eds. Elizabeth C. Traugott \& Bernd Heine, J. Benjamins, AmsterdamPhiladelphia, pp. 313-329.

Torner Castells, Sergi 2007. De los adjetivos calificativos a los adverbios en “-mente”: semántica y gramática, Visor Libros, Madrid.

Vigueras Ávila, Alejandra 1983. "Sintaxis de los adverbios terminados en -mente en el habla culta de la ciudad de México", Anuario de Letras, 21, pp. 119-145. 